\title{
Spatial Pattern of Underground Space Development in Major Cities in China: Evaluation and Analysis
}

\author{
Xiaochun Hong $\mathbb{D}^{1}$ and Xiang Ji $\mathbb{D}^{1,2}$ \\ ${ }^{1}$ School of Mechanics and Civil Engineering, China University of Mining and Technology, Xuzhou, Jiangsu 221116, China \\ ${ }^{2}$ Jiangsu Collaborative Innovation Center for Building Energy Saving and Construction Technology, \\ Jiangsu Vocational Institute of Architectural Technology, Xuzhou, Jiangsu 221116, China
}

Correspondence should be addressed to Xiang Ji; jixiang0615@yeah.net

Received 23 October 2021; Revised 15 November 2021; Accepted 17 November 2021; Published 24 December 2021

Academic Editor: Feng Xiong

Copyright (c) 2021 Xiaochun Hong and Xiang Ji. This is an open access article distributed under the Creative Commons Attribution License, which permits unrestricted use, distribution, and reproduction in any medium, provided the original work is properly cited.

\begin{abstract}
Underground space development has gradually become an organic part of China's urban development and construction. Comprehensively developing underground space scientifically and rationally to give full play to its comprehensive benefits is the main problem faced by China's underground space development at this stage. This research starts with the measurement of the level of urban underground space (UUS) development. This paper constructs a UUS development level measurement indicator system, which is composed of Construction of UUS (D1), urban economic development indicators (D2), and urban population development indicators (D3), which has 12 secondary indicators, and then we use entropy-TOPSIS method to quantitatively evaluate the development level of underground public space in 39 prefecture-level cities and above in my country and analyze its spatial differentiation. The results show that the urban agglomeration has the characteristics of "high-high" cluster distribution with the development level of underground space. However, the overall level of underground space development in China's major cities is not high and there are apparent differences in the level of UUS development. In terms of spatial distribution, the sustainable development level of cities in the eastern coastal regions of China is relatively high, with towns in the central and northeastern areas ranking second and western towns and northeastern cities ranking the lowest. At the same time, we found that there is a mismatch between the underground space development index and the economic population development index in the evaluation index. Finally, some suggestions are put forward to realize the balanced development of UUS development in our country.
\end{abstract}

\section{Introduction}

Since the reform and opening up, with the rapid development of China's economy, the amount of underground space development in China's cities has increased year by year [1]. Since 1997, UUS development regulations have increased year by year (Figure 1). On October 28, 2019, the Global Underground Space Development and Utilization Shanghai Summit released the "Shanghai Declaration" on the global underground space development and utilization. One of the essential topics is: using underground space to save land resources and improve land-use efficiency. Underground space development is to meet current and future human needs for the rapid growth of cities. However, conflicts, resource waste, and environmental effects caused by the fragmented story are becoming increasingly prominent. Therefore, promoting the coordinated development of underground spaces in different regions is essential to promote sustainable urban development [2].

From the perspective of the overall development pattern of UUS in China, the lack of top-level design and overall planning at the national strategic level has led to the widespread waste of underground space resources in different degrees, and the shallow resources in more developed cities have been almost exhausted; the development of underground space industry is uneven; the underground space industry chain still needs to be integrated; the market potential has not been fully tapped; and the investment in the core competitiveness of underground space majors such as scientific and technological innovation, information 


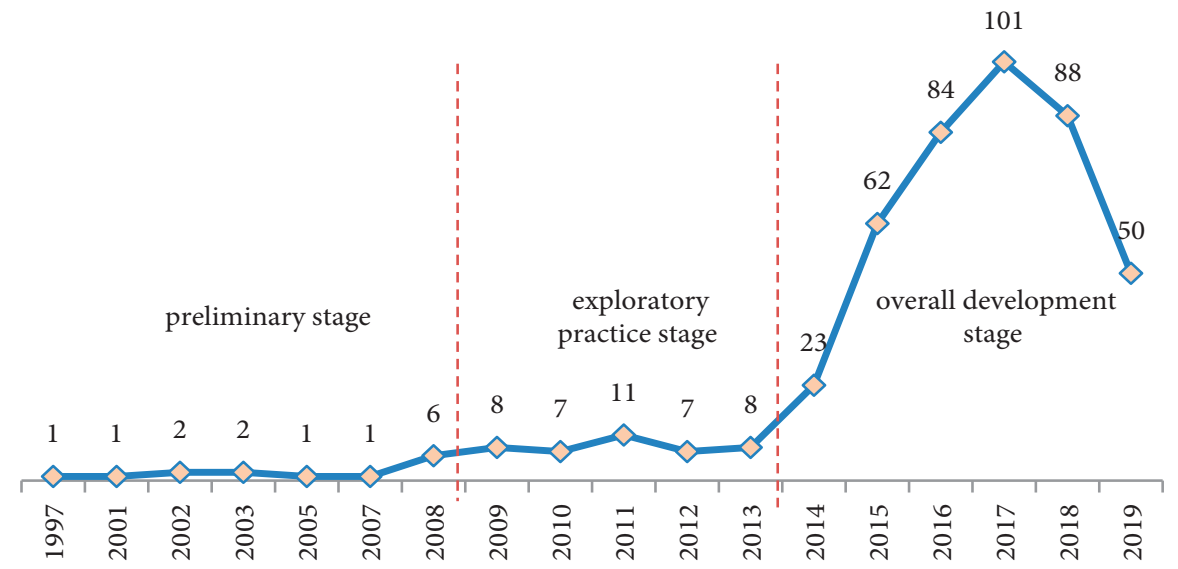

FIgURE 1: Number of laws and regulations promulgated related to UUS development.

technology services, cutting-edge technology, and intelligence cultivation is insufficient, and these obvious weaknesses need to be improved [3]. Among them, the unbalanced development of UUS is particularly prominent so that it has been affected in the construction of underground space governance system, planning and construction, and information management construction and has been regretted by people from all walks of life committed to the cause of underground space [4]. Under the background of changing urban problems and great differences in the three-dimensional process of urban space, the development of UUS in China is facing the urgent needs of adjustment, optimization, transformation, and upgrading. China has made great progress in the development of UUS, but there are also many conflicts and unresolved problems.

In this context, analyzing the influencing factors of UUS development level in China, revealing the distribution of constituent elements of underground space development level in major cities in China, and exploring the spatial pattern of UUS development level in China can effectively provide decision support and services for the government, enterprises, and the public. The evaluation and analysis of the UUS development level is an essential subject of comprehensive statistics. Related research on the relationship between the development level of urban underground space and economic development and the relationship between the development level of urban underground space and urban population development has been relatively mature [5]. Still, urban underground space is a supplement to urban ground space and its expansion. The current situation is affected by various factors such as the development of ground land, the population distribution of the city in which it is located, population vitality, and the economic development of the city in which it is located. Therefore, it is essential to construct a measurement index system of urban underground space development levels composed of multiple factors, to explore the distribution of urban underground space development levels and various relationships between indicators and the development level of urban underground space [6]. Based on the socio-economic statistical data, this study quantitatively evaluates the development level of UUS in China. By constructing the UUS development level measurement index system including underground space development, urban development, and urban population distribution and comprehensively using the enterprise TOPSIS method, this paper measures the UUS development level and analyzes the spatial pattern, which provides the index model and method support for the evaluation of urban development level in China and provides a reference for the monitoring of urbanization process. The rest of this paper is organized as follows. The second section analyzes the factors affecting UUS development and the measurement method of the development level of UUS through literature review. The third section introduces the research area and data. The fourth section presents the research methods, including constructing the UUS development level index system, the evaluation method, and the index system's weighting method. Next, Section 5 will elaborate on the results and discussion. Finally, in Section 6, this paper gives conclusions, suggests suggestions, and looks forward to the future research process.

\section{Literature Review}

The research on the measurement of UUS development has a long history, including UUS construction planning, spatial planning, ecological planning, and so on. For example, the density ratio model of UUS is used to measure the density of UUS [7], the low-carbon effect of UUS [8], the sustainability evaluation of UUS [9], the geological environment analysis of UUS [10], the assessment of underground space resources [11], the vitality measurement of UUS [12], the capacity measurement of underground space [13], the accessibility measurement of UUS [14], and so on; we can see that the measurement and design of UUS include all aspects of the whole life cycle from planning to planning, from design to construction, and from management to operation and maintenance. Furthermore, since underground space does not exist independently and is often built under urban roads or urban plots, its development is related to geological characteristics [15], the land price [16], location of development projects [17], urban economic development level [11], advantage degree of UUS construction [18], connection degree with urban planning $[19,20]$, and the development 
potential of UUS [21]. In recent decades, the rapid development of China's economy and the immediate improvement of urbanization have effectively promoted urban population agglomeration. The process of urbanization in developed countries has entered the middle and late stages as early as last century [22]. Therefore, most of the relevant theories and case studies outside China in this study focus on the last century. Relevant theories and case studies on China have been concentrated in recent years. Our research matched this situation with the differences in development stages in different regions.

The function and layout of UUS are critical factors for developing and utilizing UUS. Boivin (1991) described the Montreal underground pedestrian street network, which connected 44 buildings and 9 subway stations [23]. Polzin (1999) analyzed the relationship between subway and land use by challenging some traditional concepts [24]. Admiraal proposed a bottom-up underground space planning idea, involving several studies on three-dimensional land planning conducted by cob in the Netherlands and obtained a practical method called "underground space development potential map." This concept has been used in the southern Netherlands to avoid the waste of resources caused by topdown underground space Planning [25]. Bélanger discussed the development model of the underground network and its future as an essential urban infrastructure and paid attention to the origin and transformation of the Toronto underground pedestrian network to illustrate its multidimensional nature. In addition, Li et al. (2016) studied the demand and driving factors of underground space in three subway station areas [17]. Peng et al. (2018) studied the land use and underground space utilization around two subway stations in Shanghai and Osaka, Japan. By summarizing the analysis of underground space function and layout distribution of the two cases, they outlined the station centre layout and commercial street centre layout modes represented by the two cases. The station centre layout emphasizes the smooth transfer of people between different transportation modes. The central layout of the commercial street not only emphasizes traffic transfer but also emphasizes the intensive commercial development and a higher plot ratio of the space under the urban road. It is pointed out that with the urban development, the development model of urban underground public space will change from the central layout of the commercial street to the central design of the station [26]. Through the above search on the influencing factors affecting the development of UUS and the development and utilization of UUS, we can see that the product of UUS includes urban underground transportation facilities [27], underground municipal facilities $[28,29]$, underground comprehensive disaster prevention facilities [30], underground public service facilities [31], demand and scale prediction, spatial layout, planning control, facility construction, and so on [32]. Its core is to underground some urban functions to meet users' diversified needs for urban operations [33]. These factors have different effects in promoting the development of urban underground space. The level of economic growth is a decisive factor restricting the development and utilization of urban underground space. Domestic and foreign practical experience shows that when the per capita GDP is 200 to 300 US dollars, the product of urban underground space can gradually satisfy urban economic development that requires rapid development of urban underground space when the per capita GDP is 500 to 2,000 US dollars. When the per capita GDP exceeds 2,000 US dollars, the function and scale of urban underground space development are flourishing. The early development of urban underground love space was affected by the international situation, national protection, and civilian needs. The influence of city scale on urban underground space is reflected in the underground space development index corresponding to the population scale. The large scale of underground space in cities with large population-scale will derive more diverse functions of underground space. Due to the limitations of urban geological conditions, geographic environment, and underground space development technology, urban underground space development has also undergone corresponding changes. In addition, human psychological factors and the shaping of the urban underground space environment affect the vitality of the underground space, thereby affecting urban underground space development.

Urban underground space development is comprehensively affected by the development project itself, urban economic growth, and urban population development. In recent years, China has carried out a large number of UUS development projects. Therefore, it has also established a guidance and control index system with Chinese characteristics formulated by different government agencies [34-37]. At the same time, many scholars began to pay attention to the spatial distribution characteristics of UUS construction. Qualitative and quantitative methods have been used in many studies. The qualitative analysis mainly focuses on the process [38], path [39], and causes [40] of UUS development. Quantitative research specifically includes a comprehensive evaluation of UUS development level [40], driving force analysis of UUS development [41], and trend analysis [3, 42]. The concentration of UUS construction in economically developed areas is the primary trend of UUS construction, which will promote the construction and development of urban agglomeration systems [43]. Although many existing studies have explained the structure of UUS, there are few studies on the integration of underground space, urban development, and population.

Standardization, weighting, and aggregation in measurement methods are usually the basic UUS construction evaluation $[44,45]$. The selected weight method is the crucial step of evaluation, and the weight results directly affect the conclusion of the study. Weighting methods can be divided into two categories. The subjective method determines the weight coefficient of each index through a comprehensive consultation score, mainly including the analytic hierarchy process (AHP) [46] and the Delphi method [47]. The subjective weight calculation method is greatly affected by the questionnaire object. Targeted conclusions can be drawn when studying a single city. However, once targeting a more comprehensive range of research objects, this method may exaggerate or reduce the impact of some indicators, and it is 
easy to lead to inaccurate reflection of the relationship between indicators. Objective methods determine the weight of each index according to the internal relationship and the change degree between different indexes, mainly including principal component analysis (PCA) [48], entropy method [49], grey associative analysis [50], and factor analysis [51]. Therefore, the selection of enterprise TOPSIS method as the method of this study can meet the needs of this study on the measurement of UUS construction level in different regions and different economic development levels in China.

\section{Study Areas and Data}

3.1. Study Areas. By the end of 2019, China's total prefecture level and above cities have reached 337, including four municipalities directly under the central government and 222 prefecture-level cities. The development of UUS has a strong correlation with urban economic development [20] and urban population development [52]. At present, the cities that develop UUS on a large scale in China are mainly concentrated in the municipalities directly under the central government, significant regional cities, and other subway construction cities. China's urban construction subway sets a threshold for economic development and urban population. Combined with the previous literature review, we know that the development level of urban underground space is affected by the city scale, urban economic development level, urban geological environment, underground space development technology, and underground space environmental design. In addition, the level of social and economic development promotes the development of urban underground space to different degrees [53]. Therefore, we comprehensively consider the current product of urban underground space in China and find that these factors have a high degree of consistency in the threshold requirements for urban underground space development and urban rail transit construction [54]. Therefore, 39 cities with subway construction in China are selected as the research area of this study (Figure 2).

Up to now, the latest data obtained by various indicators are the data in 2020. But as we know, COVID-19 has had a more significant impact on the city construction in the world by the end of 2019; especially in early 2020, during the period of preventing and controlling COVID-19, China's city construction activities almost stagnated. With the Chinese government's rapid and effective epidemic prevention and control policy, China's urban construction and economic development are gradually on track. However, there is still a big gap compared with the situation in 2019. In particular, the economic development data of Wuhan and Guangzhou affected by the epidemic in 2020 cannot reflect the actual objective status of urban economic development. Therefore, among the different databases of COVID-19, we chose 2019 data as the primary data of this study.

3.2. Data Resource. The data used in this study are from China's official statistical yearbook and research report.
Among them, $D_{11} \sim D_{15}$ data are from the blue book 2020 on UUS construction in China and China Urban Construction Statistical Yearbook 2020; $D_{21} \sim D_{23}, D_{31}$, and $D_{32}$ data are from China Urban Statistics Yearbook 2020; and $D_{24}$ and $D_{33}$ data are from China urban vitality Research Report 2019.

\section{Study Methods}

4.1. Construction of the Index System. Urban underground space development belongs to the category of urban construction. Urban construction is closely related to urban economic development level, population-scale, and population density. Therefore, UUS development involves urban development, society, economy, and other aspects and is an auxiliary means for planners to select schemes. Therefore, the index system is composed of the UUS construction index $\left(D_{1}\right)$, urban economic development index $\left(D_{2}\right)$, and urban population index $\left(D_{3}\right)$ (Figure 3 ). Following the principles of independence, practicability, and operability, the index layer is constructed. We determine the measurement index system of the UUS development level, including 3 criteria layer indexes and 12 index layer indexes [55].

The comprehensiveness and simplification of indicators should be fully considered in extracting indicators. Neither important indicators nor too many indicators should be omitted, resulting in cross-indicators and increasing the difficulty of evaluation. The index system should be clearly positioned and structured to avoid redundancy. The meaning of the index is clear and convenient for quantitative evaluation [56]. According to the existing research results and the purpose of this study, the measurement index system of the UUS development level is summarized in Table 1.

4.2. Calculating Index Weight Using Entropy Weight Method. Index weighting is the basis of evaluation. The index system consists of qualitative and quantitative indicators. Therefore, it is necessary to deal with the indicators dimensionless first and then carry out comprehensive weighting. The entropy weight method calculates the weight based on the dimensionless results, which are more objective. The primary process is as follows:

(1) Index dimensional standardization

The indicator units and dimensions in the indicator system are different and cannot be compared directly. Therefore, the indicators need to be dimensionless. When we deal with positive indicators, the standardized calculation method is as follows:

$$
x_{i j}^{\prime}=\frac{x_{i j}-x_{j}^{\min }}{x_{j}^{\max }-x_{j}^{\min }} .
$$

When we deal with negative indicators, the standardized calculation method is as follows:

$$
x_{i j}^{\prime}=\frac{x_{j}^{\max }-x_{i j}}{x_{j}^{\max }-x_{j}^{\min }} .
$$




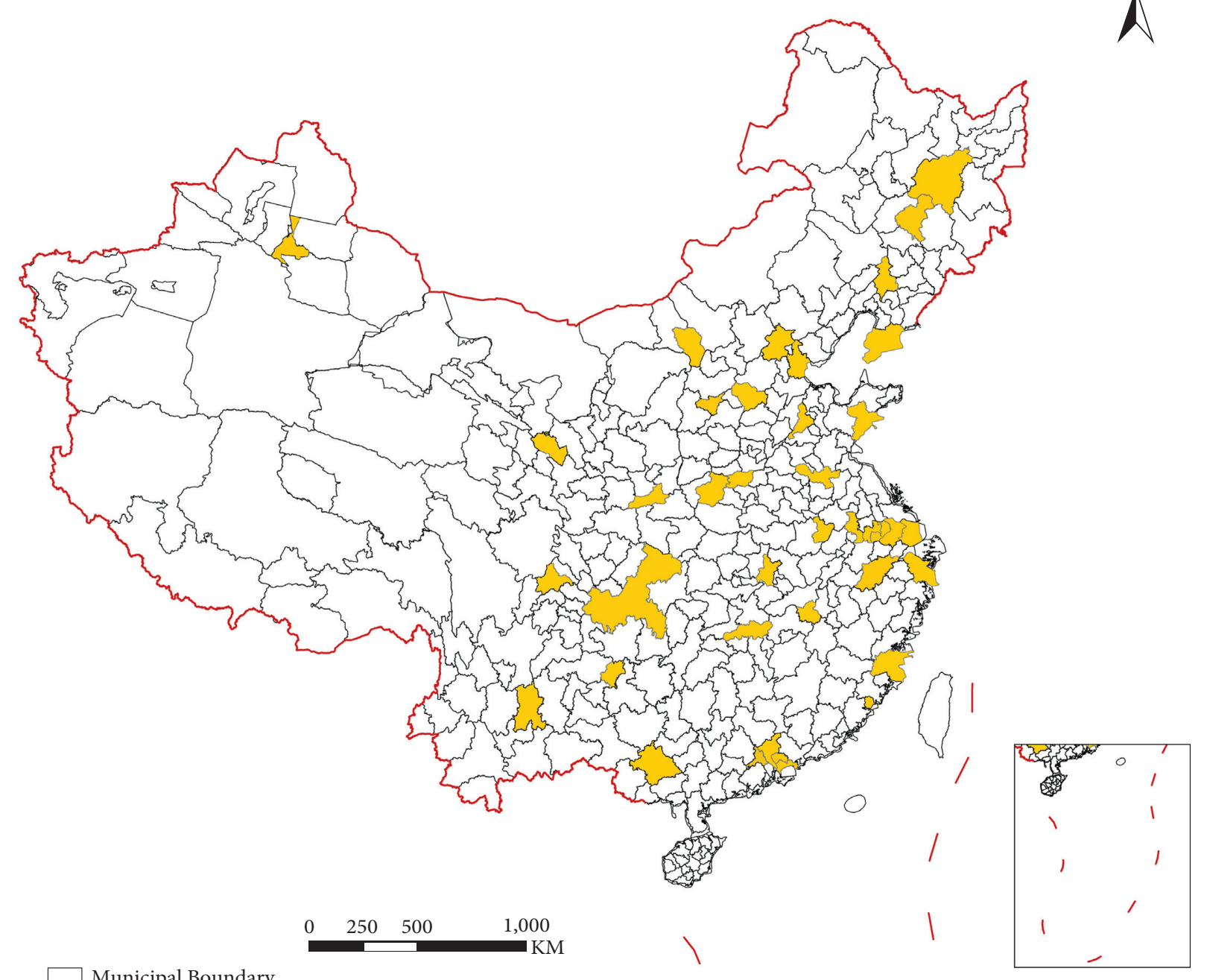

$\square$ Municipal Boundary

$\square$ Location of Research Object

FIgURE 2: Space distribution of major Chinese cities based on the level measure of underground space development.

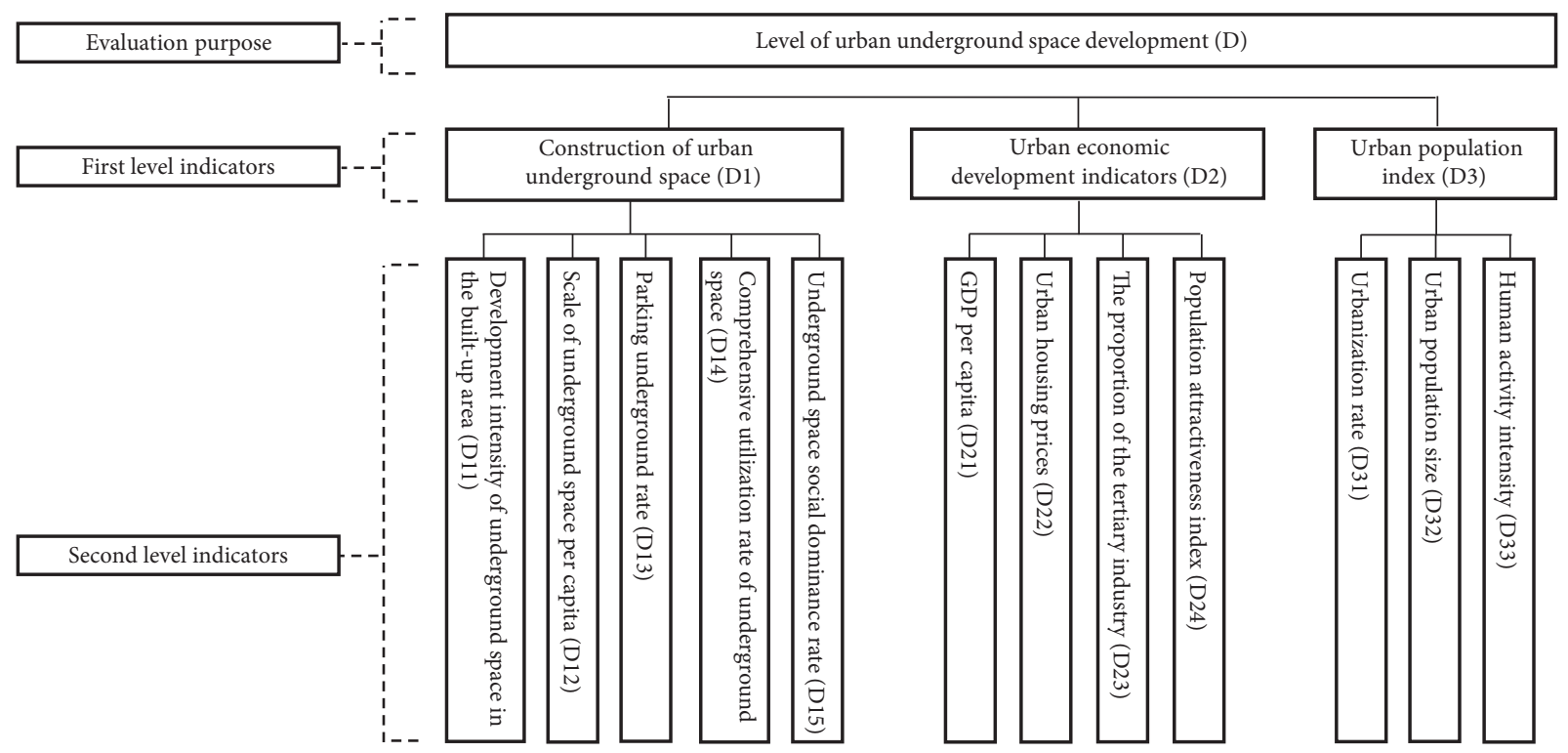

FIgURE 3: Index system for UUS development level. 
TABLE 1: Summary table of the index system of UUS development level.

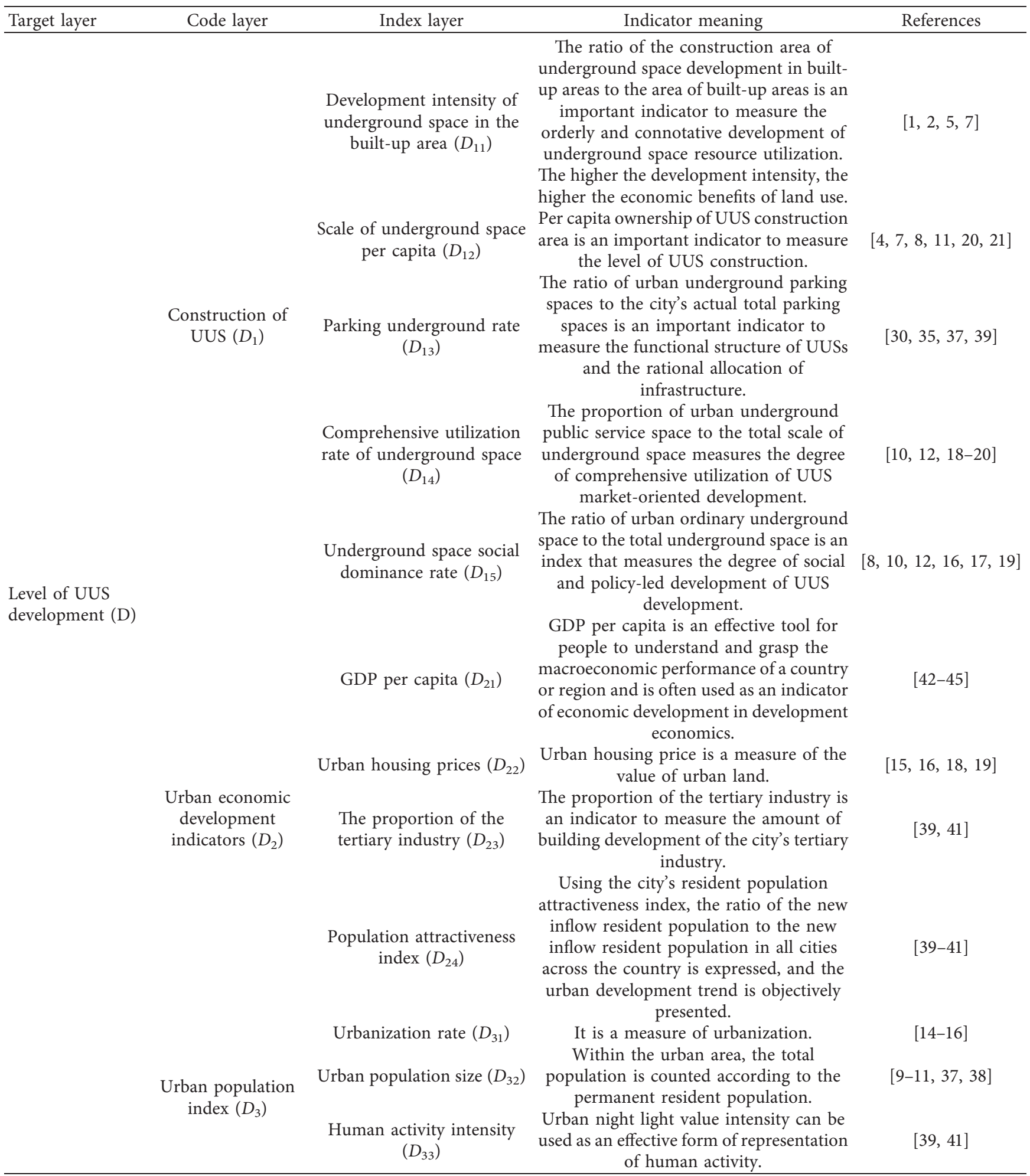

(2) Normalization of index results

We further translate the standardized values according to a specific range to unify the index results into a comparable area, to eliminate the negative value or poor comparability of modelling results after dimensionless processing of some indexes. The standardized numerical translation calculation method is as follows:

$$
x_{i j}^{\prime \prime}=H+x_{i j}^{\prime},
$$


where $H$ is the translation amplitude of the standardized value, taken as 1 .

(3) Dimensionless index value

The index value is dimensionless. Generally, the data is dimensionless by using the numerical specific gravity distribution. The calculation method is as follows:

$$
y_{i j}=\frac{x_{i j}^{\prime \prime}}{\sum_{i=1}^{n} x_{i j}^{\prime \prime}} .
$$

(4) Calculation of entropy

$$
e_{j}=-\frac{1}{\ln n} \sum_{i=1}^{n} y_{i j} \ln y_{i j} \text {. }
$$

(5) Calculation of difference coefficient

$$
g_{j}=1-e_{j}
$$

where $j=1,2, \ldots p$.

(6) Calculation of index weight

$$
\omega_{j}=\frac{g_{j}}{\sum_{j=1}^{P} g_{j}}
$$

where $j=1,2, \ldots p$.

4.3. TOPSIS Model. TOPSIS is a typical measurement method, which can make full use of the information of the original data, and its results can accurately reflect the gap between the evaluation schemes. The basic process of the model is: first unify the original data matrix with the index type (generally forward processing, i.e., the larger the value of the index, the better the representative object itself. The indicators constructed in this study are positive indicators), obtain the forward matrix, standardize the forward matrix to eliminate the influence of each index dimension, find the best scheme and the worst scheme in the limited system, then calculate the distance between each evaluation object and the best approach and the worst scenario, and obtain the relative proximity between each evaluation object and the best system, which can be used as the basis for evaluating the advantages and disadvantages. This method has no strict restrictions on the distribution of data and the content of samples, and the data calculation is relatively simple. The specific steps are as follows.

4.3.1. Matrix Standardization. Assuming that there are $n$ objects to be evaluated and $M$ evaluation indexes (which have been forward converted through the first step), the forward matrix is as follows:

$$
X_{i j}=\left[\begin{array}{cccc}
x_{11} & x_{12} & \ldots & x_{1 m} \\
x_{21} & x_{21} & \ldots & x_{2 m} \\
\ldots & \ldots & \ldots & \ldots \\
x_{n 1} & x_{n 2} & \ldots & x_{n m}
\end{array}\right] .
$$

The processed data is subjected to vector normalization, and the following formula transforms the vector normalization:

$$
b_{i j}=\frac{a_{i j}}{\sqrt{\sum_{i=1}^{x_{i j}} a_{i j}^{2}, \quad i=1, \ldots, m, j=1, \ldots, n}} .
$$

The most significant feature of this method is that after normalization, the square sum of the same attribute value of each scheme is 1 . Therefore, it is often used to calculate the Euclidean distance between each scheme and a virtual scheme (such as ideal solution point or negative ideal solution point) and weight it to obtain the weighted normalization matrix.

Assuming that there are $n$ evaluation objects, the standardized matrix of $m$ evaluation indexes is $Z$, as follows:

$$
Z=\left[\begin{array}{cccc}
z_{11} & z_{12} & \ldots & z_{1 m} \\
z_{21} & z_{21} & \ldots & z_{2 m} \\
\ldots & \ldots & \ldots & \ldots \\
z_{n 1} & z_{n 2} & \ldots & z_{n m}
\end{array}\right] .
$$

4.3.2. Determining Positive Ideal Solution $C^{*}$ and Negative Ideal Solution. Suppose the $j$-th attribute value of positive ideal solution $C^{*}$ is $c_{j}^{*}$, and assume that the $j$-th attribute value of negative ideal solution $C^{0}$ is $c_{j}^{0}$.

$$
\begin{aligned}
& \text { positive ideal solution } c_{j}^{*}=\underset{i}{\max c_{i j} j=1,2, \ldots n}, \\
& \text { negative ideal solution } c_{j}^{0}=\min _{i} c_{i j} j=1,2, \ldots n .
\end{aligned}
$$

4.3.3. Calculating the Euclidean Distance between Each Scheme and the Ideal Point and the Negative Ideal Point. According to Euclidean distance, the distance $d_{i}^{*}$ and $d_{i}^{0}$ between scheme $i$ and the ideal and negative points are calculated as follows:

$$
\begin{aligned}
& d_{i}^{*}=\left[\sum_{j=1}^{n}\left(c_{i j}-\max _{i}\left\{c_{i j}\right\}\right)^{2}\right]^{1 / 2}, \\
& d_{i}^{0}=\left[\sum_{j=1}^{n}\left(c_{i j}-\min _{i}\left\{c_{i j}\right\}\right)^{2}\right]^{1 / 2} .
\end{aligned}
$$

4.3.4. Calculating the Comprehensive Measure Index. We use equations (11) and (12) to calculate the distance $d_{i}^{*}$ from each scheme to the positive ideal solution and the distance $d_{i}^{0}$ from the negative ideal solution. We then calculate the comprehensive evaluation index $C_{i}$ for each city $i$. The calculation method is as follows:

$$
C_{i}=\frac{d_{i}^{0}}{d_{i}^{0}+d_{i}^{*}}
$$




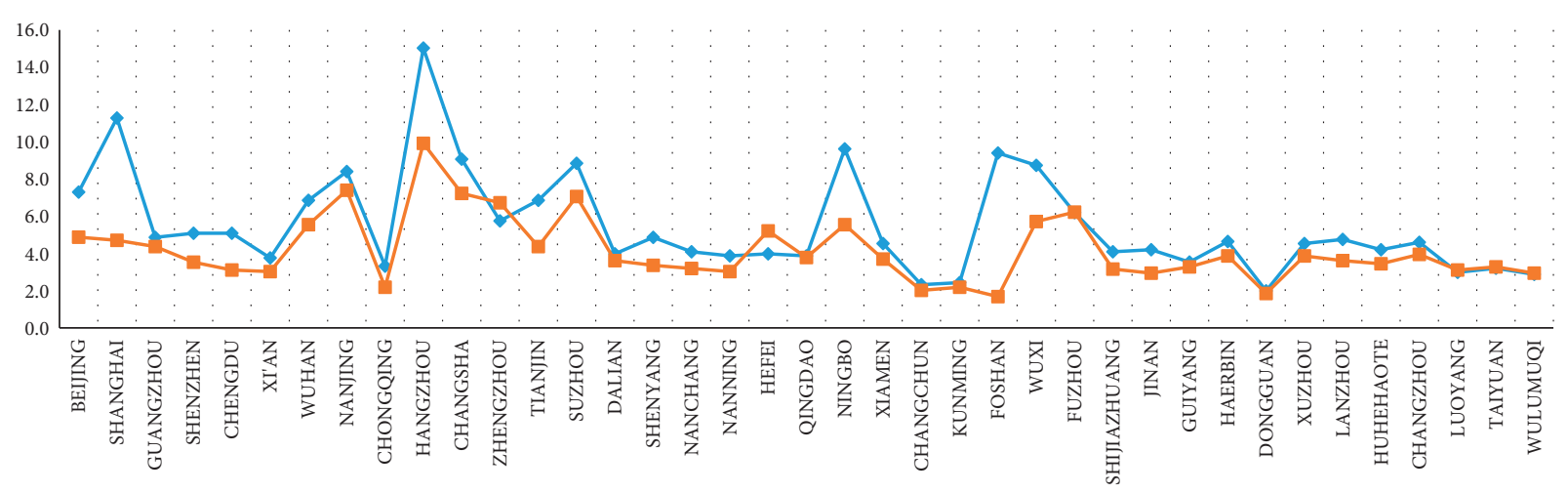

$\longrightarrow$ Development intensity of underground space in the built-up area (D11)

- Scale of underground space per capita (D12)

Figure 4: The distribution of the data for the indicators $D_{11}$ and $D_{12}$.

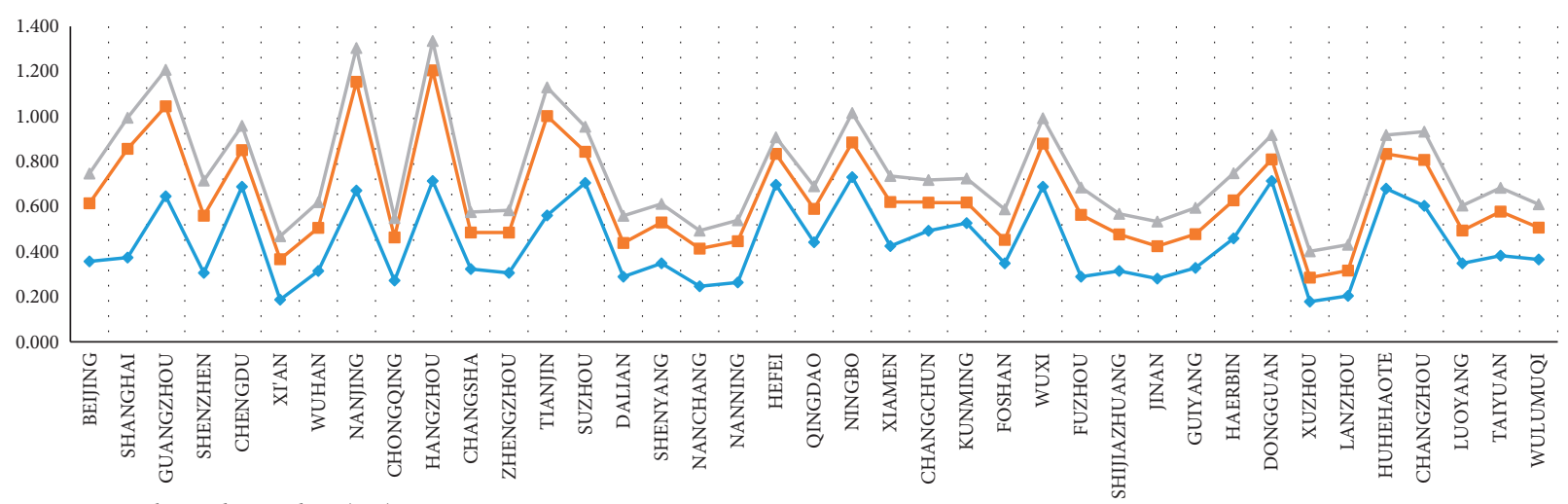

- Parking underground rate (D13)

- Comprehensive utilization rate of underground space (D14)

$\rightarrow-$ Underground space social dominance rate (D15)

Figure 5: The distribution of the data for the indicators $D_{13}, D_{14}$, and $D_{15}$.

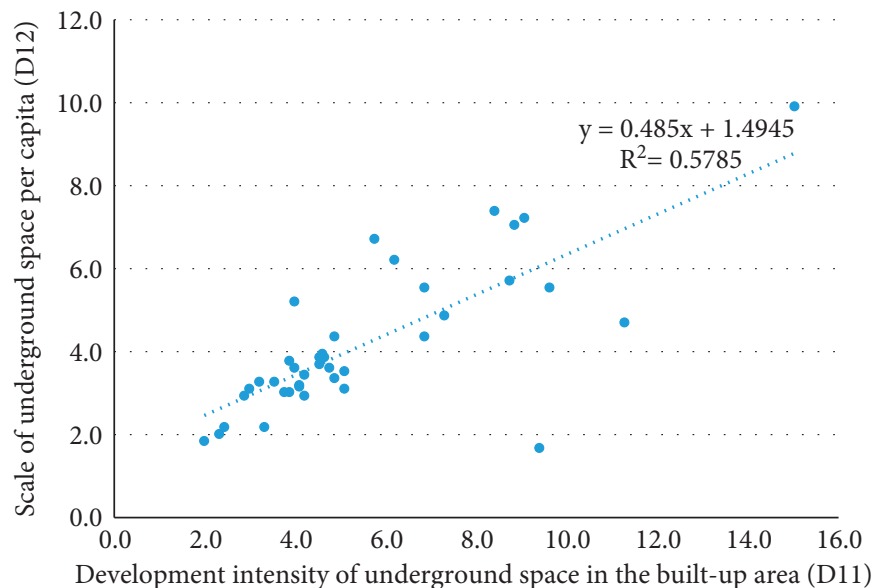

Figure 6: Correlation analysis of $D_{11}$ and $D_{12}$. 


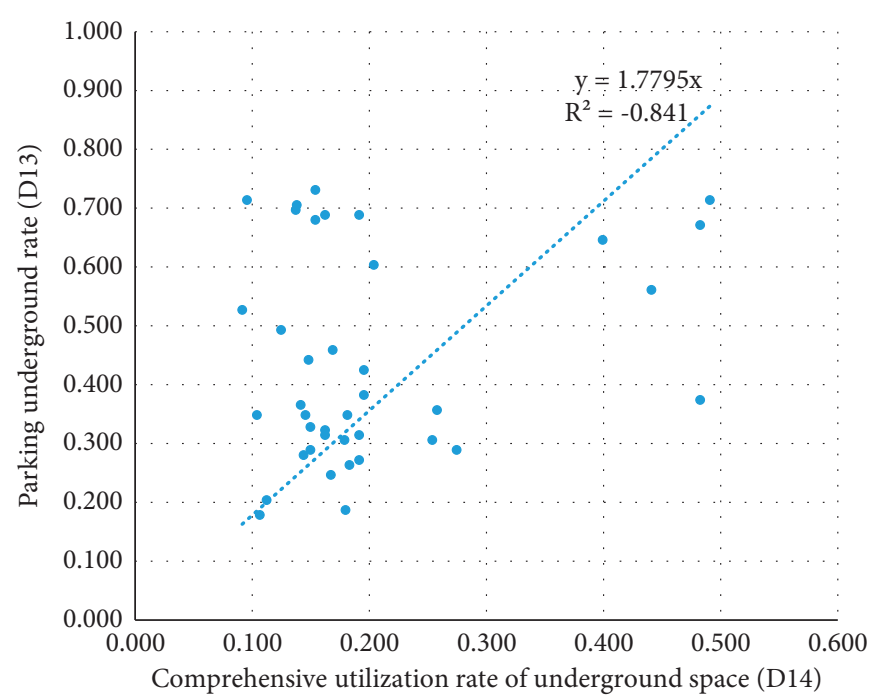

Figure 7: Correlation analysis of $D_{14}$ and $D_{13}$.

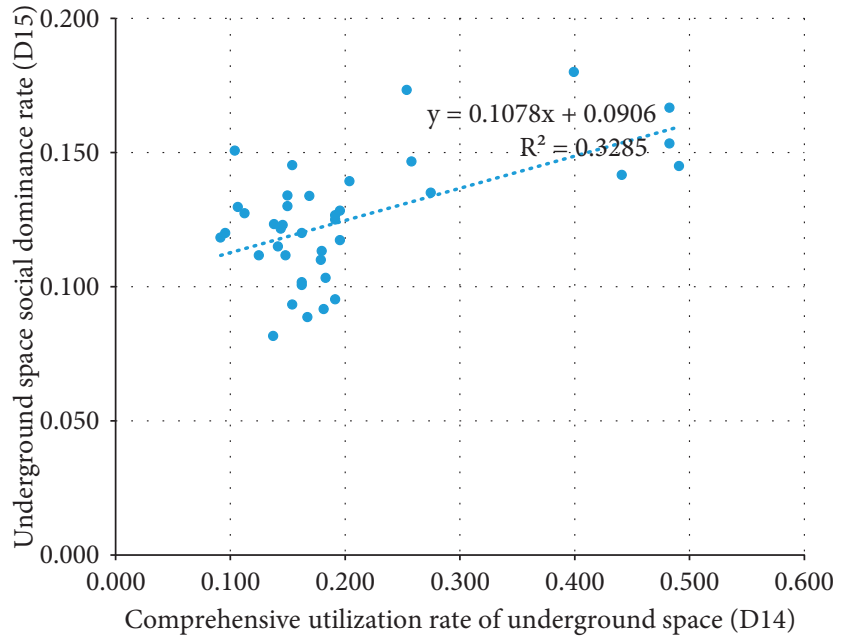

FIgURe 8: Correlation analysis of $D_{14}$ and $D_{15}$

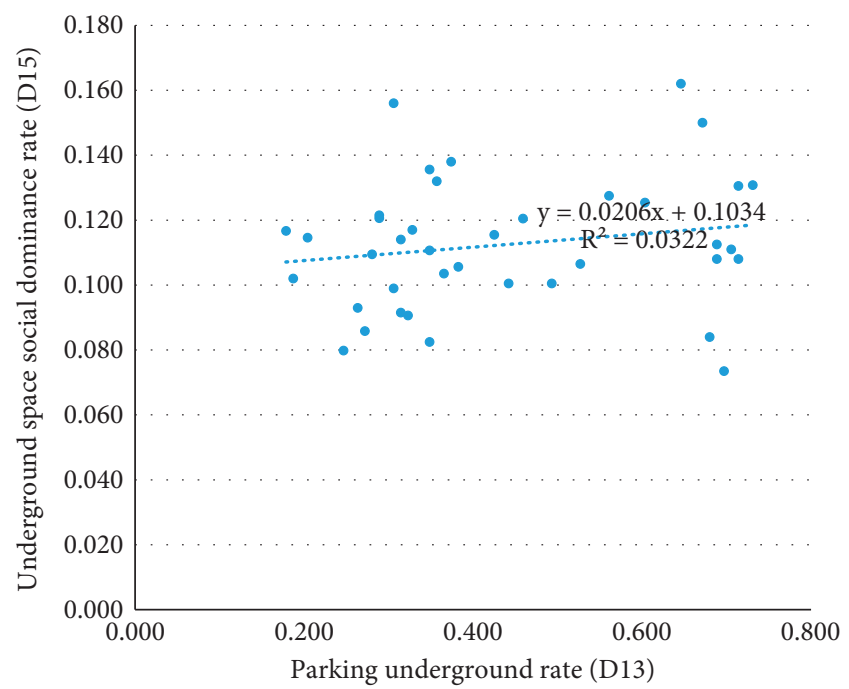

Figure 9: Correlation analysis of $D_{13}$ and $D_{15}$.

\section{Results and Discussion}

\subsection{Analysis of Results}

5.1.1. Statistical Results of Indicators. Our evaluation of the development intensity of underground space in the built-up area (D11) shows that the top ten cities are Hangzhou, Shanghai, Ningbo, Foshan, Changsha, Suzhou, Wuxi, Nanjing, Beijing, and Wuhan (Figure 4) ). Our evaluation of the per-capita size of underground space (D12) shows that the top ten cities are Hangzhou, Nanjing, Changsha, Suzhou, Zhengzhou, Fuzhou, Wuxi, Ningbo, Wuhan, and Beijing (Figure 4). The evaluation result of the parking underground rate (D13) shows that the top ten cities are Ningbo, Dongguan, Hangzhou, Suzhou, Hefei, Chengdu, Hohhot, Changzhou, Wuxi, Nanjing, and Guangzhou (Figure 4). Our evaluation of comprehensive utilization rate of underground space (D14) shows that the top ten cities are Hangzhou, Shanghai, Nanjing, Tianjin, Guangzhou, Fuzhou, Beijing, Changzhou, Taiyuan, and Wuhan (Figure 5). Thus, it can be seen that although the ranking of cities corresponding to various indicators of UUS construction is slightly different, it is relatively concentrated in Shanghai, Hangzhou, Nanjing, Shenzhen, Guangzhou, Suzhou, and other economically developed cities.

However, the measurement of UUS development level is composed of UUS construction, economic development, and population development. For example, as Beijing is the capital of China, its underground space development is greatly affected by the administration. Although UUS development is significant and the degree of UUS construction is low, as the economic centre of northern China, Beijing's population, and economic development level are among the best in China. Hence, its UUS development level is not low. According to the obtained UUS construction data, we found that the development intensity of underground space in the built-up area (D11) and scale of underground space per capital (D12) has a robust correlation (Figure 6). There is also a strong positive correlation between the parking underground rate (D13), comprehensive utilization 
TABLE 2: Summary of measurement results of UUS development level.

\begin{tabular}{|c|c|c|c|c|}
\hline & $D$ & $D_{1}$ & $\mathrm{D}_{2}$ & $D_{3}$ \\
\hline Beijing & 0.63103 & 0.4525 & 0.85364 & 0.69048 \\
\hline Shanghai & 0.66136 & 0.59111 & 0.74375 & 0.75697 \\
\hline Guangzhou & 0.65725 & 0.62183 & 0.7028 & 0.56872 \\
\hline Shenzhen & 0.62155 & 0.45241 & 0.7427 & 0.73008 \\
\hline Chengdu & 0.50886 & 0.43607 & 0.43974 & 0.58511 \\
\hline Xi'an & 0.40182 & 0.19748 & 0.34907 & 0.56097 \\
\hline Wuhan & 0.43865 & 0.36847 & 0.46542 & 0.43258 \\
\hline Nanjing & 0.63474 & 0.75647 & 0.503 & 0.52357 \\
\hline Chongqing & 0.29661 & 0.15285 & 0.28027 & 0.4904 \\
\hline Hangzhou & 0.68897 & 0.83627 & 0.54571 & 0.61085 \\
\hline Changsha & 0.44395 & 0.37548 & 0.37513 & 0.53255 \\
\hline Zhengzhou & 0.41036 & 0.33867 & 0.39271 & 0.47256 \\
\hline Tianjin & 0.47549 & 0.56889 & 0.34839 & 0.43857 \\
\hline Suzhou & 0.54409 & 0.54431 & 0.494 & 0.53159 \\
\hline Dalian & 0.29167 & 0.2969 & 0.22065 & 0.26324 \\
\hline Shenyang & 0.31455 & 0.21731 & 0.25803 & 0.36588 \\
\hline Nanchang & 0.26733 & 0.14448 & 0.20228 & 0.36742 \\
\hline Nanning & 0.37518 & 0.18539 & 0.28978 & 0.49776 \\
\hline Hefei & 0.42277 & 0.39819 & 0.33864 & 0.41257 \\
\hline Qingdao & 0.35766 & 0.29766 & 0.35471 & 0.33448 \\
\hline Ningbo & 0.49194 & 0.58199 & 0.35155 & 0.39477 \\
\hline Xiamen & 0.48212 & 0.35245 & 0.45416 & 0.52579 \\
\hline Changchun & 0.24641 & 0.28512 & 0.15903 & 0.16565 \\
\hline Kunming & 0.40438 & 0.31411 & 0.32006 & 0.45475 \\
\hline Foshan & 0.46103 & 0.38683 & 0.31904 & 0.57703 \\
\hline Wuxi & 0.48672 & 0.53672 & 0.40963 & 0.38675 \\
\hline Fuzhou & 0.37854 & 0.42044 & 0.31571 & 0.35329 \\
\hline Shijiazhuang & 0.25176 & 0.19928 & 0.2339 & 0.27941 \\
\hline Jinan & 0.32663 & 0.24047 & 0.32733 & 0.34443 \\
\hline Guiyang & 0.37401 & 0.394 & 0.24138 & 0.45393 \\
\hline Harbin & 0.32989 & 0.3784 & 0.34589 & 0.10158 \\
\hline Dongguan & 0.48021 & 0.39589 & 0.35968 & 0.59385 \\
\hline Xuzhou & 0.26595 & 0.25839 & 0.14612 & 0.31533 \\
\hline Lanzhou & 0.36286 & 0.25227 & 0.27358 & 0.43259 \\
\hline Huhehaote & 0.38499 & 0.38486 & 0.29974 & 0.31561 \\
\hline Changzhou & 0.41430 & 0.46412 & 0.34372 & 0.29199 \\
\hline Luoyang & 0.22920 & 0.26472 & 0.11211 & 0.21258 \\
\hline Taiyuan & 0.38161 & 0.28277 & 0.27436 & 0.4355 \\
\hline Wulumuqi & 0.35289 & 0.2429 & 0.36047 & 0.32129 \\
\hline
\end{tabular}

TABLE 3: Corresponding standards for the closeness of UUS development level.

\begin{tabular}{lcccc}
\hline Rank & Range of $D$ & Level of development & Number of cities & Percentage of cities \\
\hline Level 1 & $>0.8$ & Excellent & 0 & 0 \\
Level 2 & $0.6 \sim 0.8$ & Good & 6 & 15.39 \\
Level 3 & $0.3 \sim 0.6$ & General & 15 & 38.46 \\
Level 4 & $0 \sim 0.3$ & Poor & 18 & 46.15 \\
\hline
\end{tabular}

rate of underground space (D14), underground space social governance rate (D15), and other indicators Figures 7-9) There is a strong correlation. In addition, there is also a strong correlation between UUS construction indicators and urban population data and urban economic development data, indicating that urban population data and urban economic development play a positive role in promoting the development of UUS.
5.1.2. Analysis of Final Measurement Results. The underground space development level of 39 major cities in China calculated by the index system constructed in this study is shown in Table 2. According to the research results of existing scholars, the closeness degree is divided into four grade standards to characterize the development degree corresponding to the development level of UUS in the study area, as shown in Table 3. 


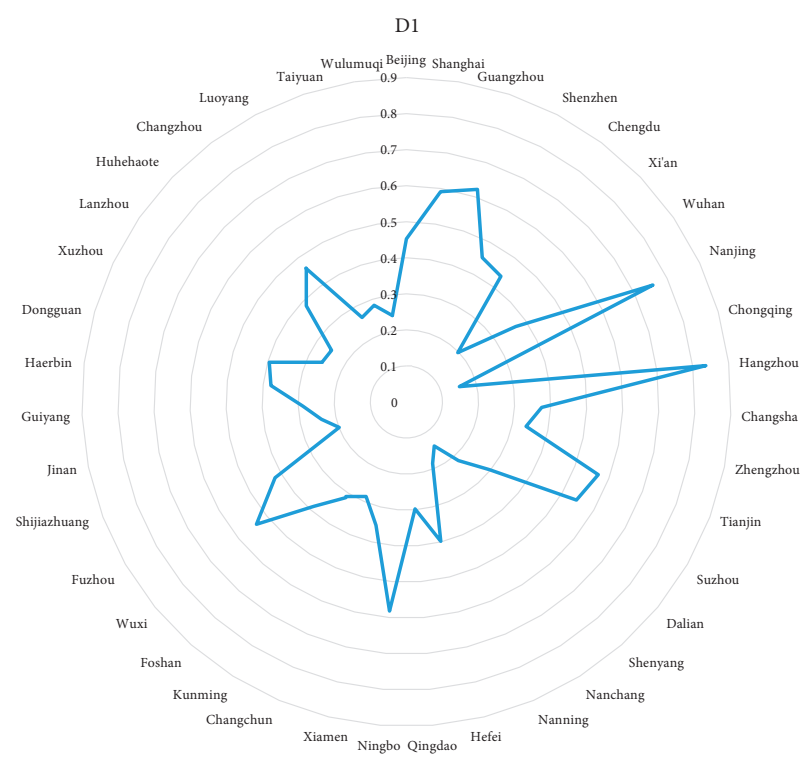

Figure 10: Radar chart of evaluation results of $D 1$.

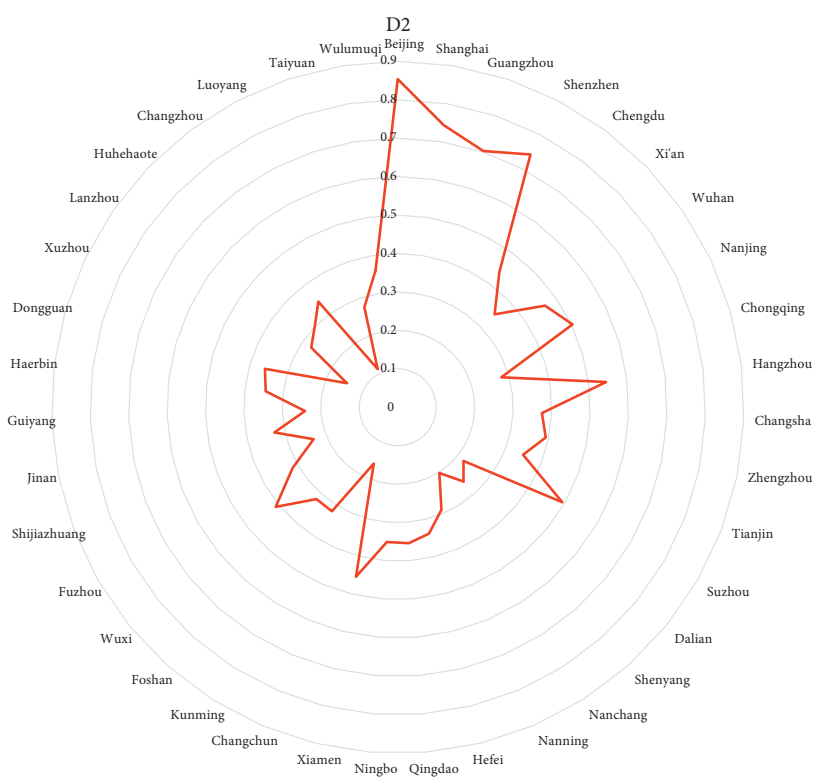

FIGURE 11: Radar chart of evaluation results of $D 2$.

Among the first-level indicators, the underground space development of Nanjing and Hangzhou far exceeds that of other cities (Figure 10); the urban economic development of Beijing and Shanghai far exceeds that of other cities (Figure 11); and the population development indicators of Shanghai, Shenzhen, and Hangzhou are relatively high (Figure 12). Thus, we can see that the distribution of the three indicators is relatively reasonable, and the index results do not fully tend to any city. Furthermore, this also proves the rationality of constructing the evaluation index system in this study. Under the influence of the first-class indicators that comprehensively reflect the development level of UUS, we can see that Hangzhou has the highest

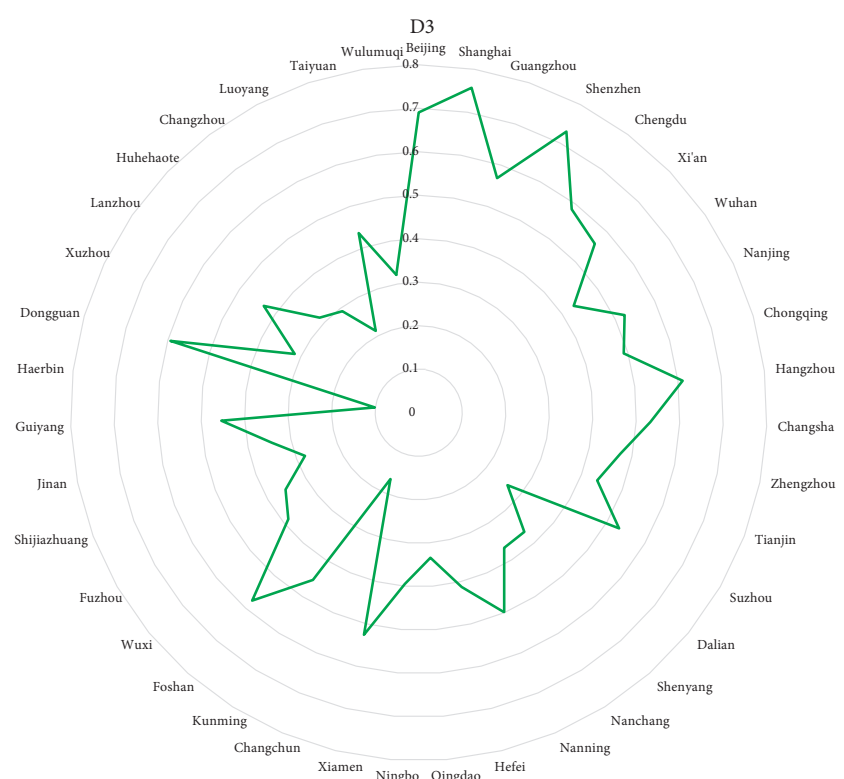

Figure 12: Radar chart of evaluation results of $D 3$.

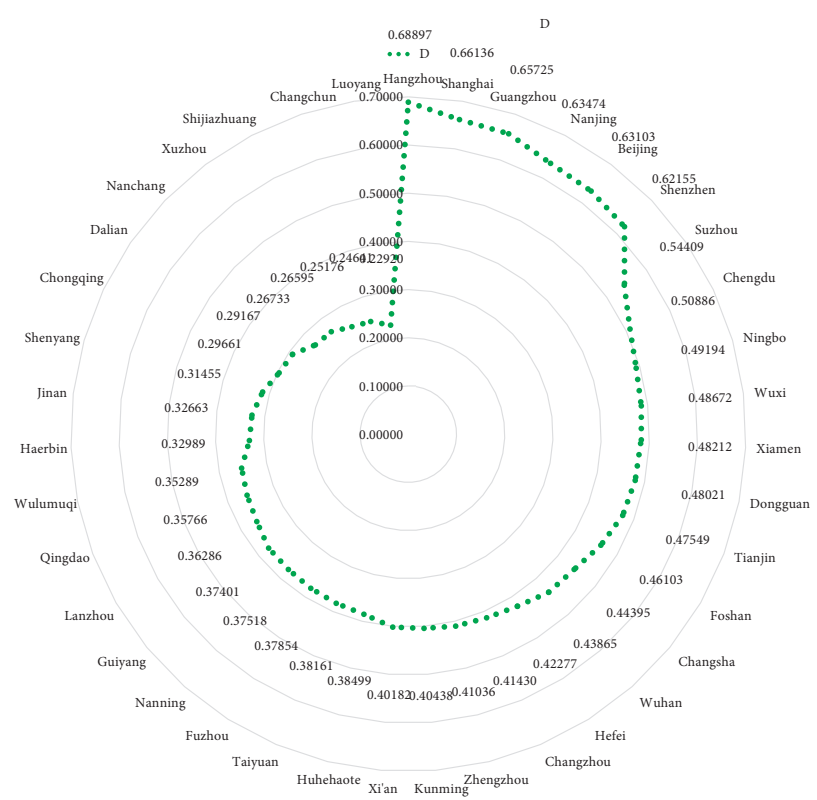

Figure 13: Radar chart of evaluation results of $D$.

development level of underground space in major cities in China, with a $D$ value of 0.68897 , which has not reached the "excellent" level.

Shanghai, Guangzhou, Nanjing, Beijing, and Shenzhen (Figure 13), accounting for $15.39 \%$ of the total sample (Table 3 ). Nearly half of the evaluation results of UUS development levels are between 0 and 0.3 . The main cities selected in this study are cities with much underground space development in recent years. We can see that the underground space development level is low overall and has an excellent local effect.

Figure 14 shows the distribution of the results of the UUS development level. The results show that the top ten cities are Hangzhou, Shanghai, Guangzhou, Nanjing, Beijing, 


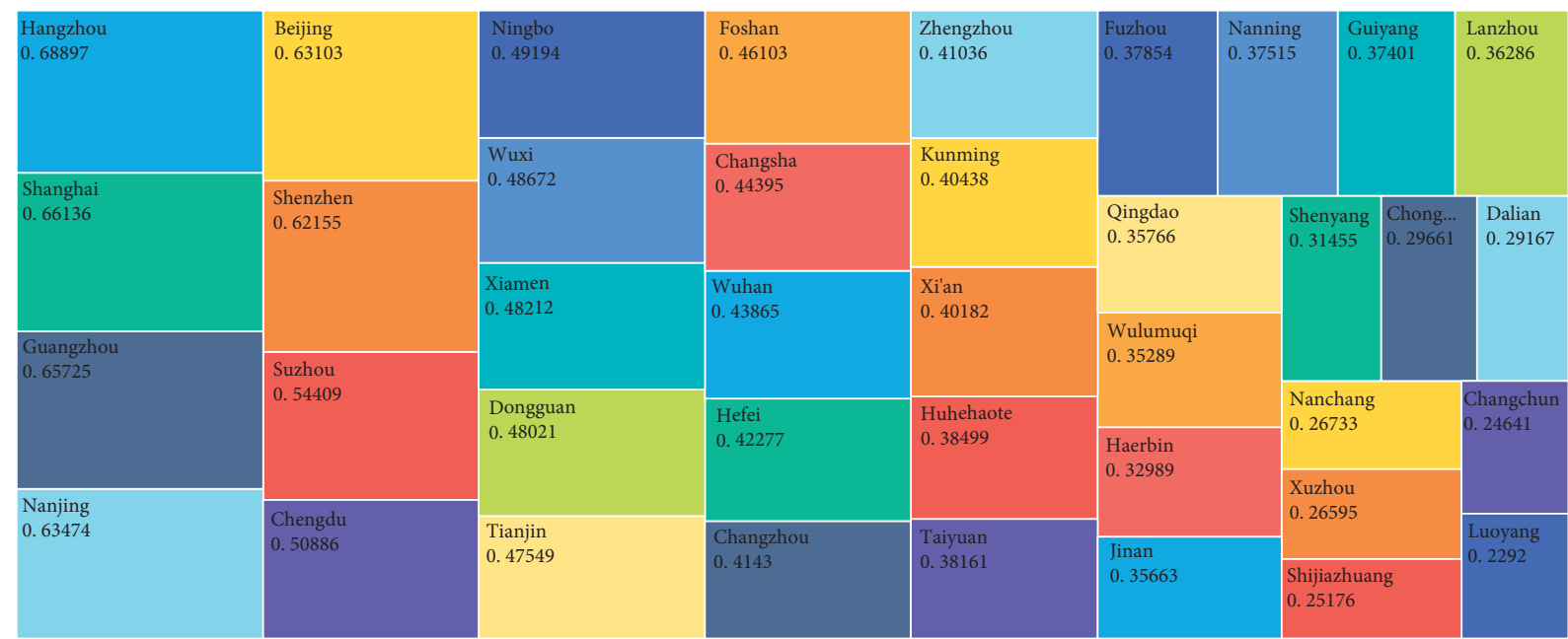

- Hangzhou Shanghai Guangzhou Nanjing Beijing Shenzhen Suzhou Chengdu Ningbo Wuxi Xiamen Dongguan Tianjin - Foshan Changsha Wuhan Hefei Changzhou Zhengzhou Kunming Xi'an Huhehaote Taiyuan Fuzhou Nanning Guiyang Lanzhou Qingdao Wulumuqi Haerbin Jinan Shenyang Chongqing Dalian Nanchang Xuzhou Shijiazhuang Changchun - Luoyang

FIGURE 14: Results distribution of $D$.

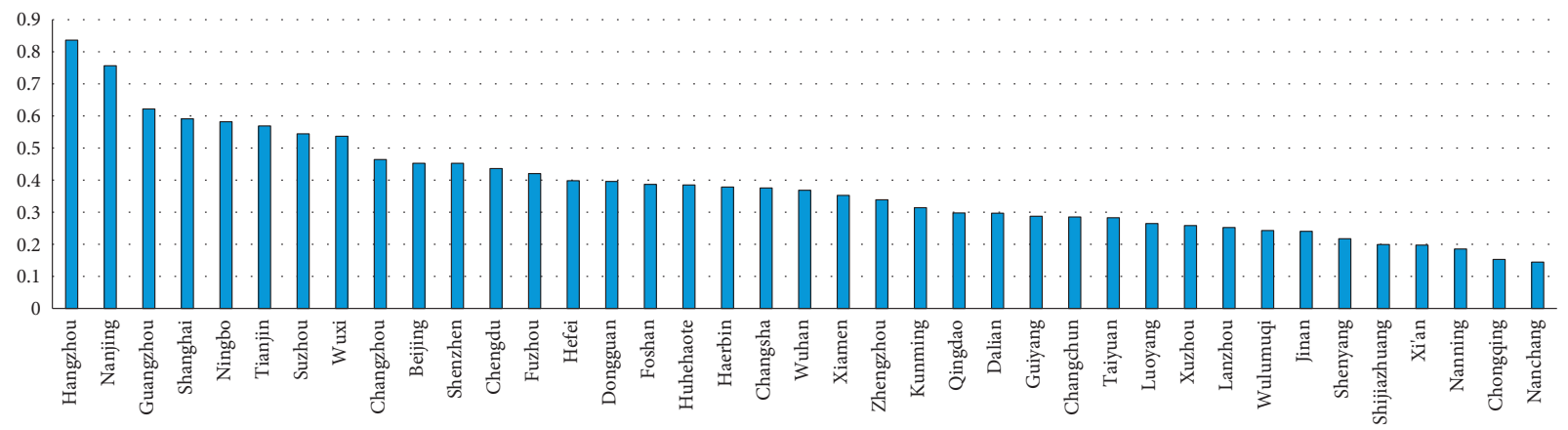

FIGURE 15: Distribution of calculation results of underground space development index.

Shenzhen, Suzhou, Chengdu, Ningbo, and Wuxi. Except that Chengdu is a central city and Beijing is a northern city, other cities are located in the southeast coastal provinces. In addition, due to the implementation of transit-oriented development (TOD) to guide urban development in recent years, many subway lines have been built, promoting the improvement of the development level of UUS.

\subsection{Spatial Distribution of Underground Space Development Level}

\subsubsection{Spatial Distribution Analysis of Subindicators}

Distribution Law of Underground Space Development Index Results. The development index of UUS is highly consistent with the spatial distribution of China's three major urban agglomerations. According to Tables 2 and 3, Hangzhou is in the first level; Nanjing and Guangzhou are in the second level' and the top ten are Shanghai, Ningbo, Tianjin, Suzhou, Wuxi, Changzhou, and Beijing (Figure 15), mainly distributed in the urban agglomerations of Yangtze River Delta and Beijing-Tianjin-Hebei metropolitan region. The urban agglomerations of Pearl River Delta are lower than other urban agglomerations. The low underground space development intensity causes the problem and per capita underground space area index (Figure 16).

Distribution Law of Urban Economic Development Index Results. Beijing, Shanghai, Shenzhen, and Guangzhou (Figure 17) rank at the forefront of urban economic development indicators. These cities are China's economic central cities. However, compared with the development indicators of UUS, only the economic development indicators of Guangzhou match the development indicators of underground space. The urban agglomerations of Yangtze River Delta economic development index is better than that of Pearl River Delta and Beijing-Tianjin-Hebei region; a new urban economic development centre with Chengdu-Chongqing region as the core has been formed in the central part (Figure 18).

By comparing and analyzing the distribution law of UUS development indicators and urban economic development 


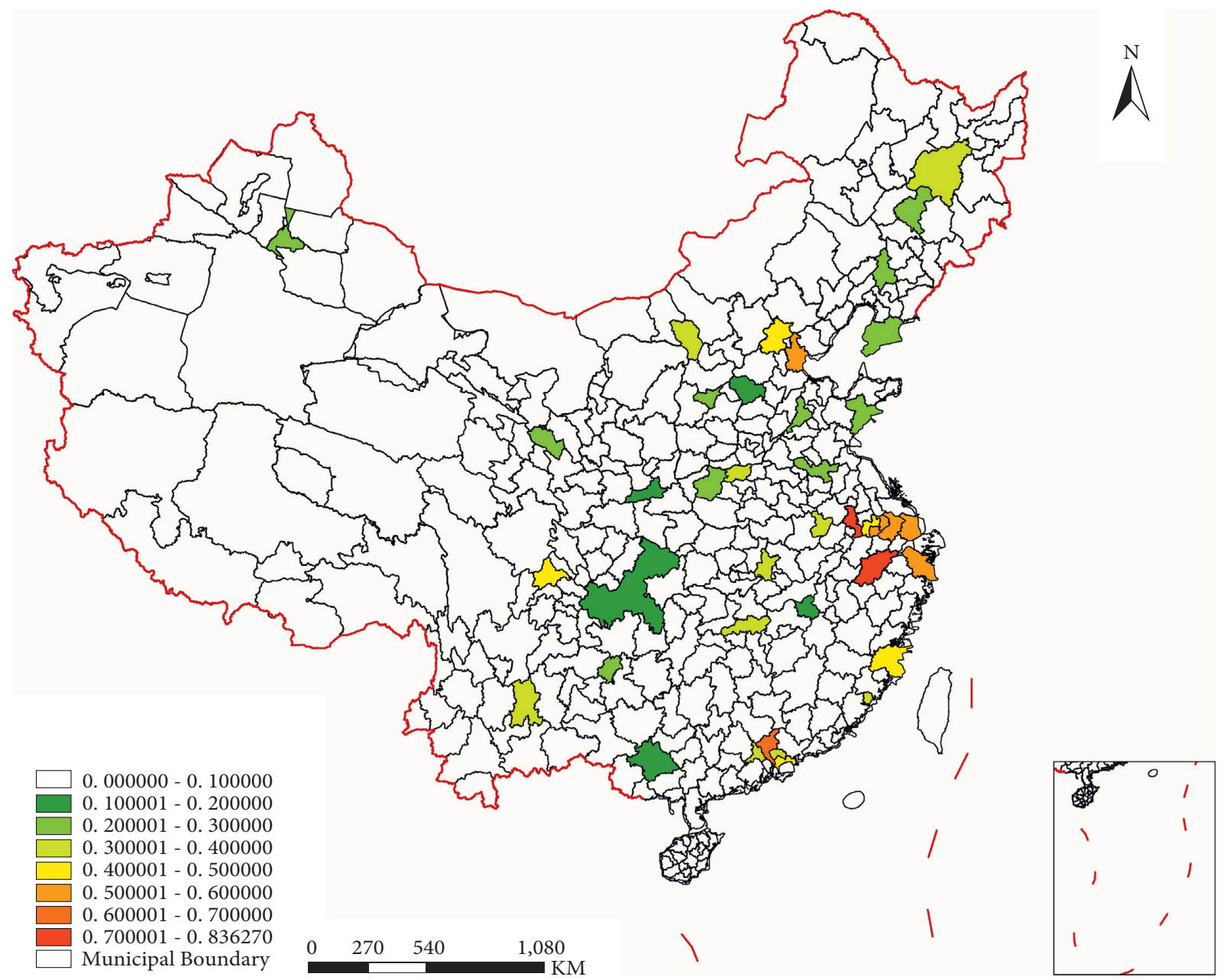

Figure 16: Spatial distribution of underground space development index calculation results.

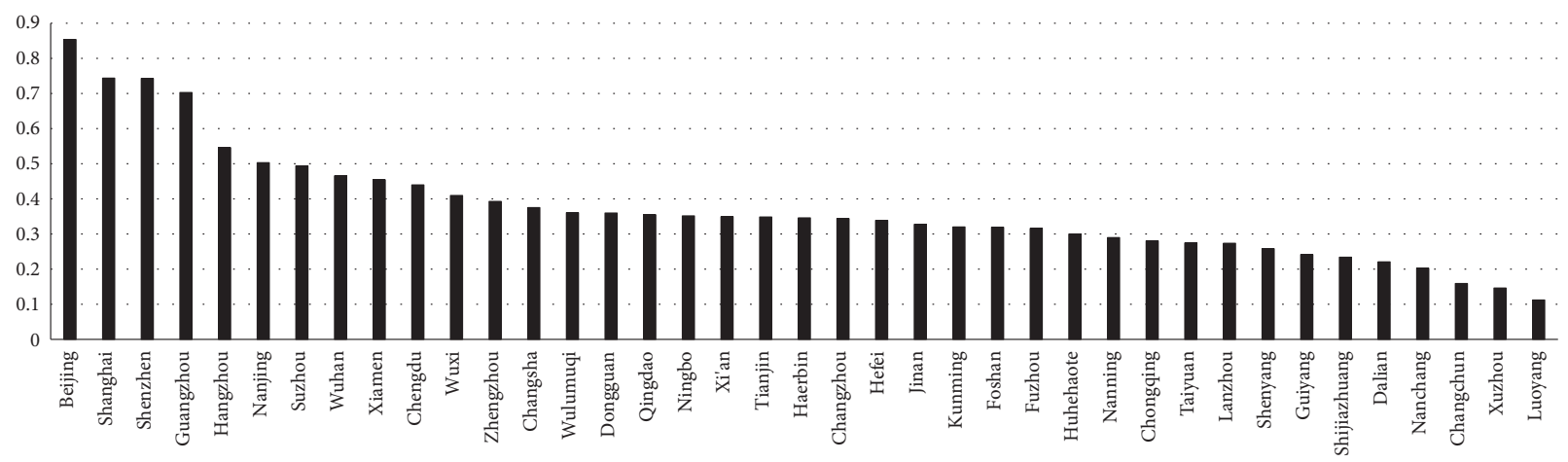

FIgURE 17: Distribution of calculation results of urban economic development indicators.

indicators, we can see that the measurement results of underground space development in Hangzhou, Nanjing, Wuxi, and Changzhou are higher than economic development, which does not match the relationship between UUS and urban economic population (Figure 19). This is mainly because these regions' early urbanization and economic development are much higher than those of other regions, making these cities realize earlier that we can solve the contradiction with economic and population expansion through the development of underground space. Guangzhou, Shenzhen, and other cities in the Pearl River Delta are located in hilly areas, with a good level of landscape economic development and low urban land utilization rate. Therefore, the demand for underground space development will be below. However, in recent years, there has been no new land development in Shenzhen. In the future, underground space development for urban expansion will promote the further development of UUS. 


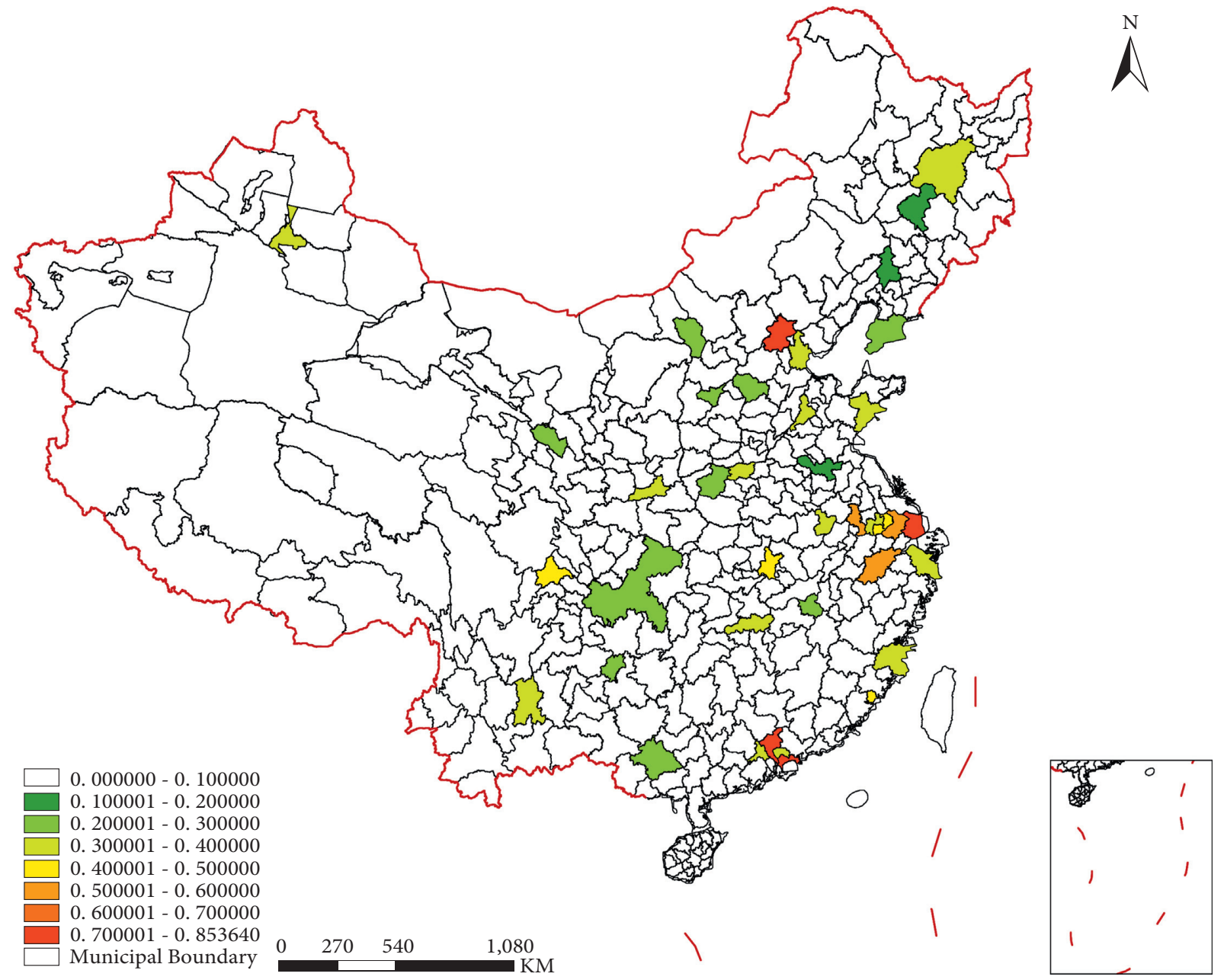

FIGURE 18: Spatial distribution of calculation results of urban economic development indicators.

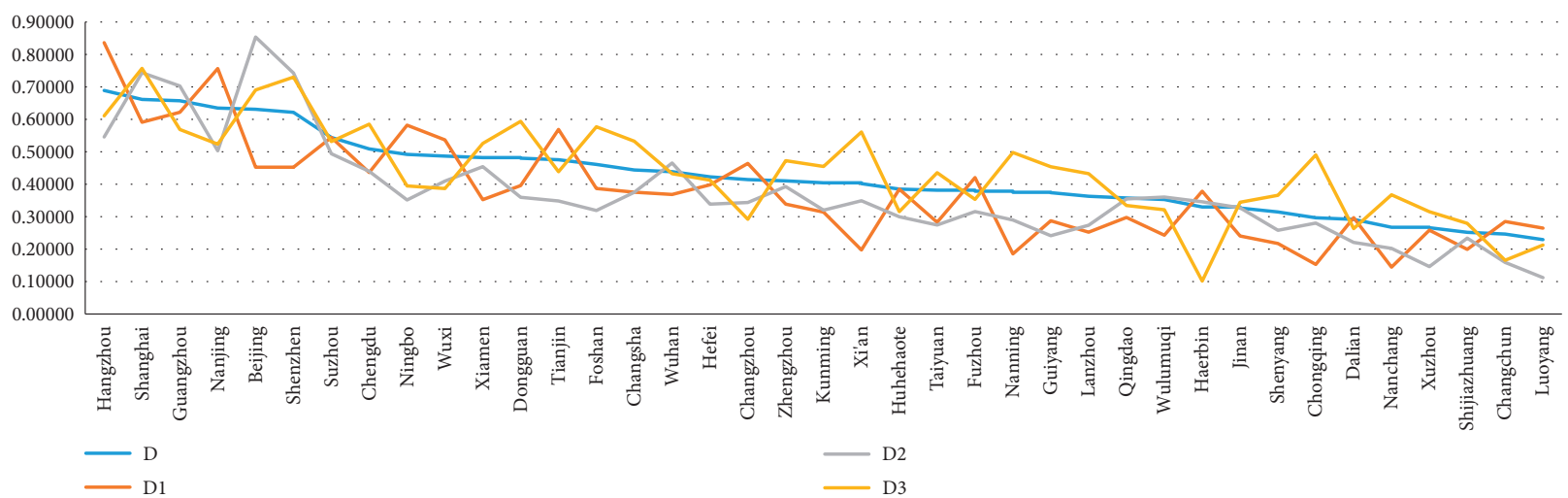

FIgURe 19: Comparative analysis diagram of the measurement results of each index.

Distribution Law of Urban Population Development Index Results. "Hu Huanyong line" is the comparison line for dividing China's population density proposed by Chinese geographer $\mathrm{Hu}$ in 1935. According to "Hu Huanyong line," the southeast half accounts for $43.8 \%$ of the national land area and $94.1 \%$ of the total population. "Hu Huanyong line" has also become the dividing line of urbanization level to some extent.
The urbanization level of most of the southeast provinces, autonomous regions, and cities along this line is higher than the national average level. Most of the northwest provinces and regions are lower than the national average level. In this study, underground space development is based on dense population and a high level of economic development. Therefore, the main cities are concentrated in the south of the "Hu Huanyong line" 


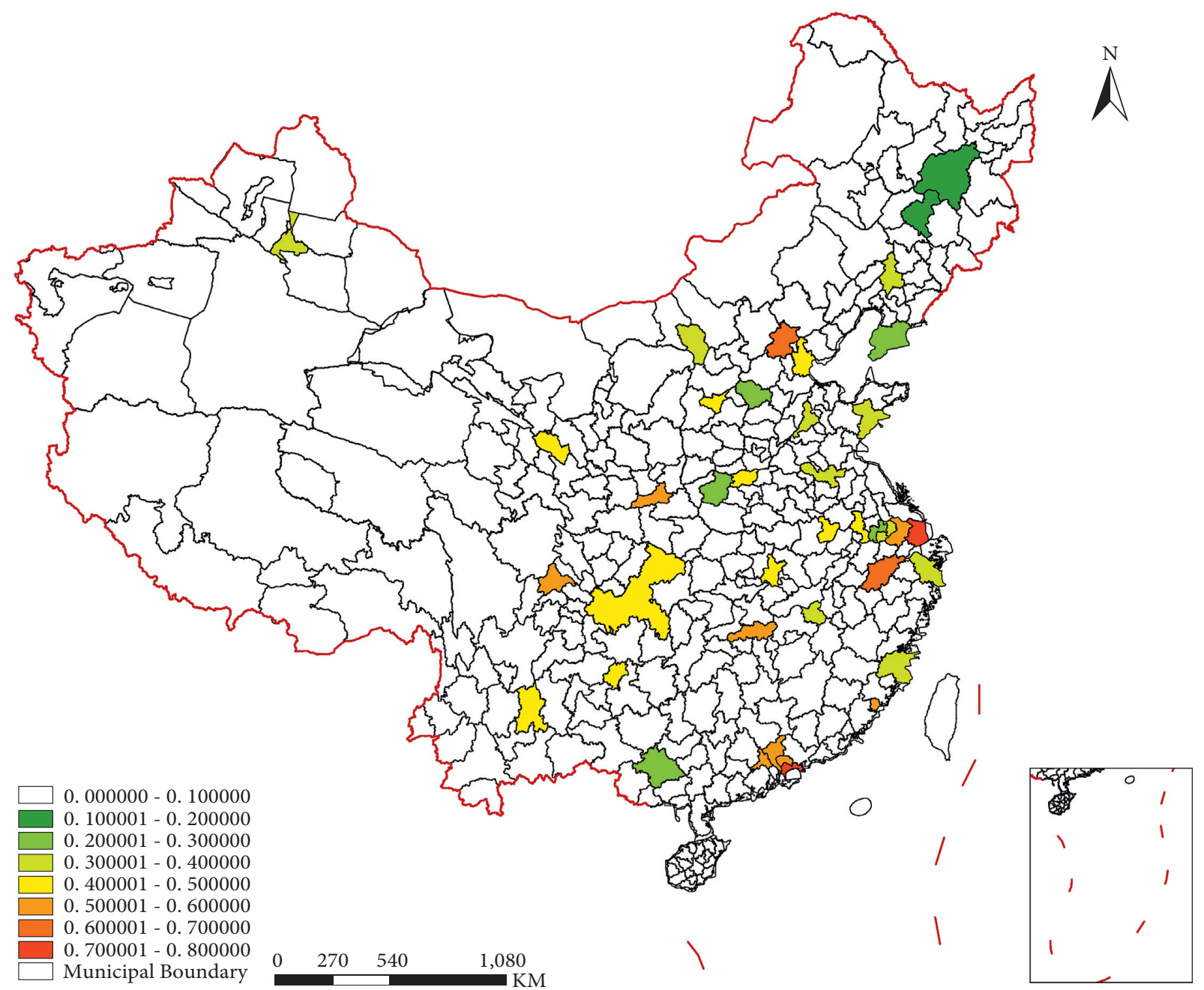

Figure 20: Spatial distribution of urban population development level indicators.

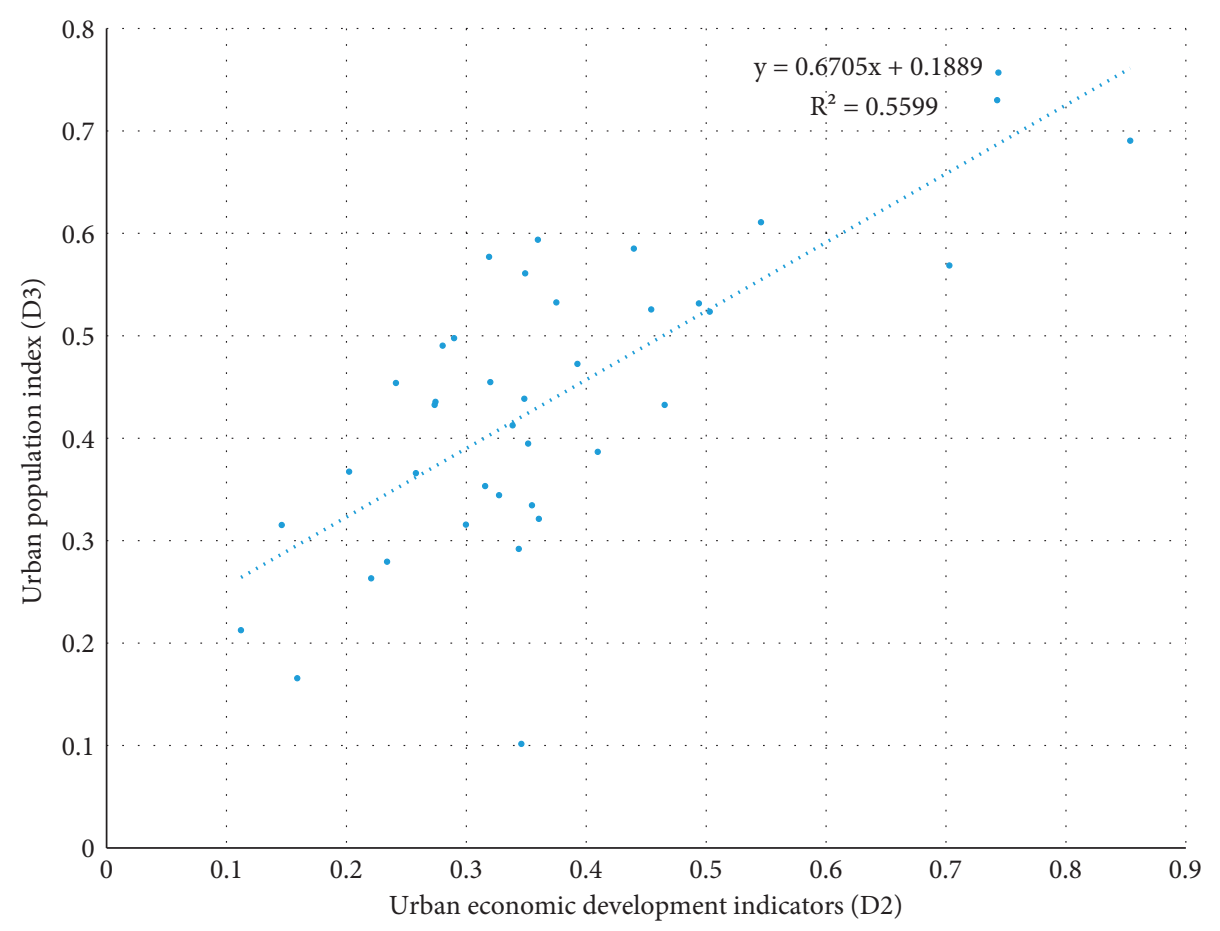

Figure 21: Correlation of the index $D_{2}$ and the index $D_{3}$. 

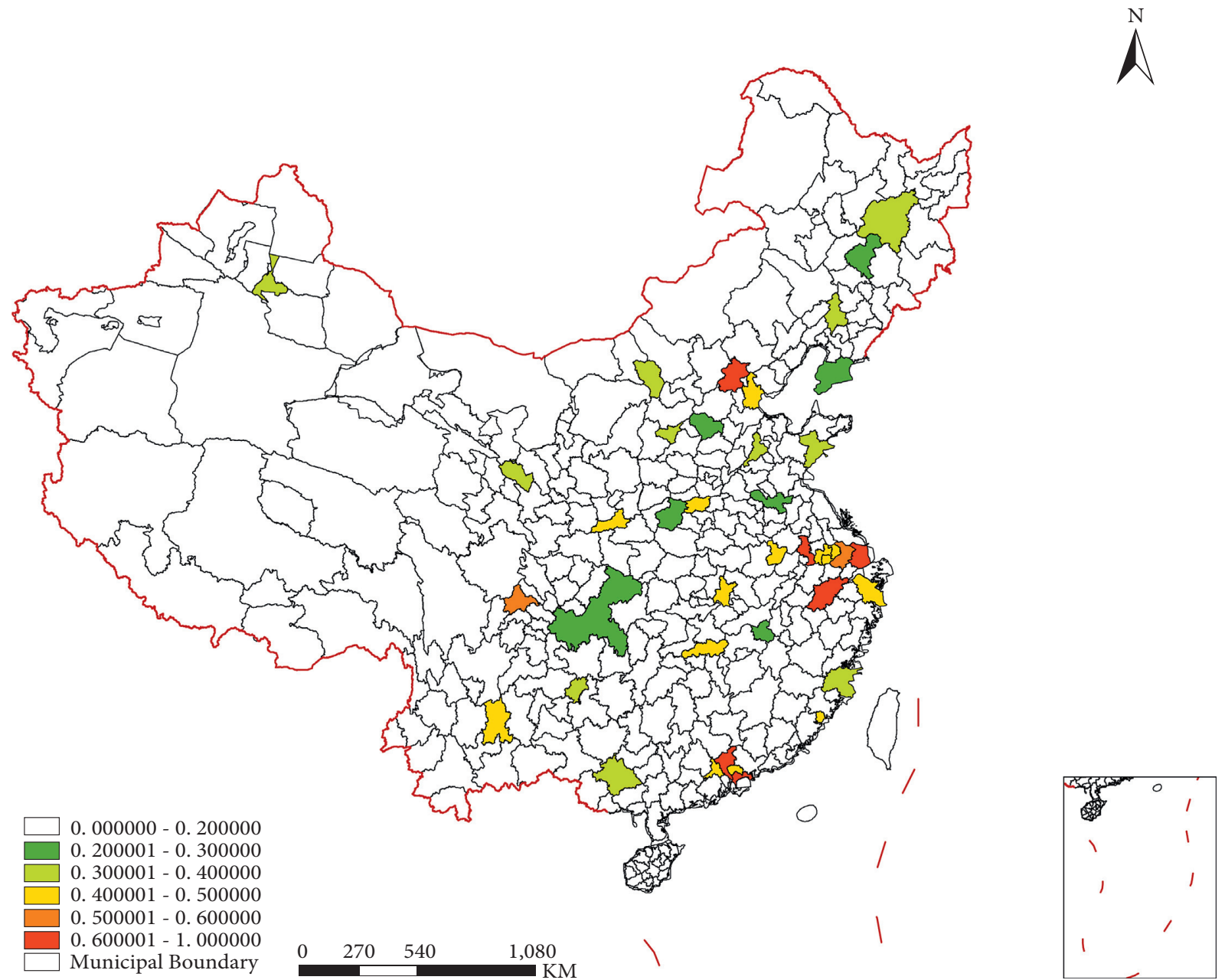

FIGURE 22: Distribution map of underground space development level in major cities in China.

(Figure 20). In addition to the higher urbanization level and human activity intensity in cities such as Dongguan and Foshan in the Pearl River Delta, resulting in higher urban population development level than UUS development and urban economic development, the population distribution results of each city are highly correlated with the level of urban economic development (Figure 21).

5.2.2. Spatial Distribution Law of Development Level. Figure 22 shows the spatial distribution law of the UUS development level in China. We can see that the urban agglomerations of Yangtze River Delta, the urban agglomerations of Pearl River Delta, Beijing-Tianjin-Hebei metropolitan region, and Chengdu-Chongqing urban agglomeration are the regions with high UUS development levels in China. The main reason is that the urban agglomerations of Yangtze River Delta and the urban agglomerations of Pearl River Delta bring together China's primary social resources, scientific and technological innovation forces, and capital market, which is conducive to promoting the development and utilization of UUS. Its underground space is ample in scale and full of functions, and also its policy support documents and management system are relatively perfect. In the urban agglomerations of Yangtze River Delta in 2019, the growth rates of the new building area of underground space in Zhejiang Province and Jiangsu Province were $12 \%$ and $9 \%$, respectively, and the growth rate of the new building area of underground space in Guangdong Province was 20\%, both far exceeding the national average growth rate of $2.05 \%$. The development level of central cities such as Changsha and Wuhan is also high. The development of underground space mainly focuses on constructing urban underground facilities systems such as subway and urban pipe galleries, which matches the current urban development pattern in China.

However, some cities such as Xi'an, Chongqing, and Nanchang have high economic development levels and population density, but the development level of underground space is deficient, which undoubtedly affects the city's sustainable development. Because the statistical calibre of this study is municipal jurisdiction, Chongqing, as a municipality directly under the central government, has a large area of a noncentral urban area, which has a significant impact on its underground space development indicator. Chongqing is an administrative region with a provincial 


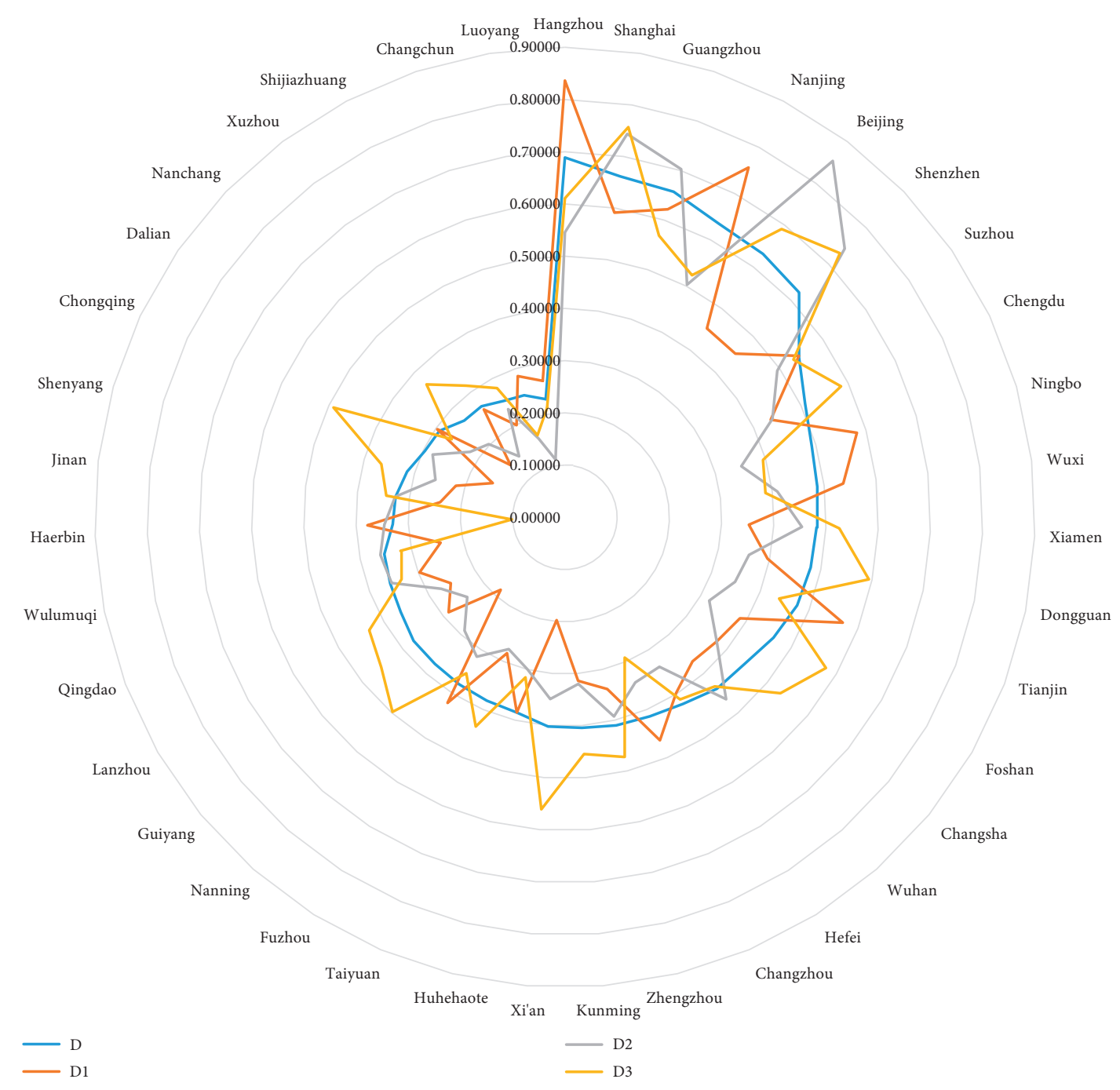

Figure 23: Comprehensive analysis of primary index measurement results.

structure, so we should combine the analysis of the results with the characteristics of the central city. What needs particular explanation is that although Chongqing is a municipal administrative region, the structure of Chongqing is a provincial structure. In other words, in addition to the main urban area of Chongqing, the urbanization process of other counties and districts is in line with the central metropolitan area. Compared with the urban area, it appears to be very slow, which undoubtedly affects the relevant indicator results of Chongqing. Suppose we put aside sites other than the central metropolitan area. In that case, the relevant indicators of Chongqing's urban economic development, population development, and underground space development are fundamental. The top one is because Chongqing is located in a mountainous area, and urban construction needs to consider the topography fully. The central metropolitan area of cluster development bears a large amount of urban population. Combined with the construction of rail transit, it connects multiple functional clusters throughout Chongqing. As far as the central metropolitan area is concerned, the development level of underground space in Chongqing is very advanced [57]. Although the population development index of Harbin and Changchun is low, their underground space develops well, mainly because Harbin and Changchun are located in the middle temperate zone [58]. The climate is characterized by warm summer and cold winter, which lasts for about five months. In cold winter, their underground space activity comfort is higher than the ground, similar to the development and utilization of Montreal underground city in Canada [59].

\section{Conclusions and Suggestions}

6.1. Conclusions. This study constructs the UUS development index system from 12 indexes in 3 aspects: underground space development, urban economic development, and urban population development [60]. The entropy weight TOPSIS method is used to measure the underground space development level of 39 major cities in China. Based on the analysis of the results, the conclusions are as follows: 
(1) The law of UUS development along urban agglomeration

As we all know, China's urban spatial pattern is mainly composed of the urban agglomerations of Yangtze River Delta, the urban agglomerations of Pearl River Delta, Beijing-Tianjin-Hebei metropolitan region, and Chengdu-Chongqing urban agglomeration. The urban agglomeration structure plays a significant role in driving regional economic development and promoting urban comprehensive benefits. As a space carrier, architecture and underground space are undoubtedly its material guarantee [61]. The 39 major cities in this study have a spatial clustering phenomenon in the comprehensive index, and the spatial clustering phenomenon of the three secondary indicators is undeniable. According to the comprehensive index, the urban agglomerations of the Yangtze River Delta, the urban agglomerations of Pearl River Delta, and the Beijing-Tianjin-Hebei metropolitan region are the areas with a high level of UUS development. As Chengdu-Chongqing urban agglomeration is located in the west, only two central cities are selected for this study case; other regional economic and population indicators are poor, so they cannot support UUS development. Therefore, the development level of UUS is the urban agglomerations of Yangtze River Delta $>$ the urban agglomerations of Pearl River Delta $>$ Beijing-Tianjin-Hebei metropolitan region $>$ Chengdu-Chongqing urban agglomeration, indicating that the development of urban population and economy in the urban agglomeration area has a significant impact on promoting the development of UUS; urban cluster development can promote the development level of UUS.

\section{(2) Unbalanced regional development of UUS}

The cities measured in this study are mainly cities with urban economic development and population development at the head of China. The development of UUS has a high correlation with urban rail transit [62]. Therefore, based on screening economic and population development, 39 cities with urban rail transit are selected. These cities are mainly distributed in the south of the famous "Hu Huanyong line," and this matches the current development law of our country. There is a spatial clustering phenomenon in the comprehensive measure $(d)$. The "high-high" clustering areas are the urban agglomerations of Yangtze River Delta, the urban agglomerations of Pearl River Delta, and the Beijing-Tianjin -Hebei metropolitan region. The overall level of other regions is not high except in Chengdu. The UUS development, economic development, and population development of the urban agglomeration in which the "high-high" cluster area is located are very balanced, indicating that the development of urban cluster is conducive to comprehensively improving various indicators of each city and promoting the development of UUS in the city. The population development level of other cities is high, such as in Zhengzhou, and the economic development level is high, such as in Chongqing. The development level of underground space is high. For example, the comprehensive index of the UUS development level in Harbin is not high. These cities have great underground space development potential. In the future, the rapid development of UUS may be realized with urban development.

\section{(3) Unbalanced development of indicators}

As an essential part of urban space, UUS serves urban residents. Therefore, its underground space development often matches urban economic development and population development. Once it does not match, there may be urban traffic congestion, low spatial efficiency, poor environmental quality, and other problems. According to the results of the three primary indicators of underground space development, urban economic development, and urban population development measured in this study, most UUS development indicators in China match well with economic development and urban population development. There are relatively few urban problems in these cities. However, there is an imbalance in the development of indicators, including the advanced development of a class of underground space indicators higher than the indicators of economic development and population development and planning the city's future development. The representative cities are Hangzhou, Nanjing, Ningbo, Tianjin, Zhengzhou, and Harbin (Figure 23). For example, Hangzhou took the construction of urban public space as the focus of urban development during the 12th Five-Year Plan period, which focused on urban construction in terms of large-scale transportation hub layout, underground corridor construction, and in-depth development, making full use of underground space to improve urban functions, alleviate traffic congestion, improve the regional environment, create more comfortable underground space and public activity facilities, and meet people's growing "quality demand" for underground space. As a result, the indicators of underground space, regional economic development, and population development develop together, mainly including Guangzhou, Beijing, Shenzhen, Xiamen, Xi'an, Nanning, Chongqing, and Nanchang. With the transformation of China's urban development from incremental expansion to stock optimization, these cities' underground space development indicators will increase rapidly in the future.

6.2. Proposal. Because of the development law of underground space in major cities in China, which shows the law of development around urban agglomeration, the development of UUS has the problems of unbalanced regional development and uncoordinated development among indicators. Therefore, in order to promote the healthy and 
balanced development of UUS in China, based on the relevant analysis of this study, we put forward the following suggestions:

(1) We should promote the sustainable development of underground space, economy, and population. The result of underground space should not rely too much on the guidance of urban policies. The involvement of social capital in promoting the development and utilization of urban underground public space is conducive to promoting the efficiency of the three-dimensional growth of the metropolitan area. The result of underground space should aim at meeting the use of urban residents. The collaborative development of underground space, economy, and population is the way to promote the rational development of UUS. This study shows that cities with a high development level of UUS generally have a high index coordination degree, confirming the necessity of balanced development.

(2) The government should take effective measures to narrow the development gap between eastern and western China and ensure the balanced development of UUS in China. Of course, this balanced development is based on the coordinated development of underground space, economy, and population. This study found significant differences in the development level of underground space between the western region and other regions in social, economic, and environmental indicators and the overall situation. At the same time, the differences between cities in the western region are also very huge. At this stage, China's "western development strategy," "finance of northeast old industrial base," "rise of central China," and other preferential policies in underdeveloped areas can provide more national support for the economic development of these regions. The population of most cases corresponding to this study is growing continuously. Therefore, under the background of sustained economic and population growth, the development difference of regional underground space development level will gradually narrow.

(3) We should support the exploration of effective evaluation methods and feedback mechanisms for UUS development vitality. On the one hand, the evaluation method can qualitatively or quantitatively reflect the UUS development level. On the other hand, the feedback mechanism can help the government find the problems hindering the development level of UUS to scientifically formulate corresponding improvement strategies and improve the efficiency of the vertical utilization of urban space.

6.3. Future Research Prospects. In fact, in addition to the three types of factors mentioned in this study, the influencing factors of UUS development level are more complex in China, such as political factors, urban rail transit construction, urban landform constraints, and urban development strategy. Under the influence of politics, the development level of underground space socialization in Beijing, China's political centre is low. Under the influence of landform, the diversity of underground space development in Chongqing is good. With the promotion of TOD development strategy, the development level of underground space in Chengdu has maintained a high level in recent years. At present, more than ten cities in China have opened or built rail transit. With the promotion of urban rail transit, the development of UUS is also developing rapidly. Therefore, in the follow-up research, we will add urban rail transit as the influencing factor affecting the development level of UUS and explore the relevant laws of the integrated development of UUS and rail transit.

\section{Data Availability}

The data used to support the study can be obtained from the corresponding author upon request.

\section{Conflicts of Interest}

The authors declare that there are no conflicts of interest regarding the publication of this article.

\section{Acknowledgments}

The authors appreciate the financial support of this work provided by the Postgraduate Research and Practice Innovation Program of Jiangsu Province, under grant nos. KYCX21-2271 and 2018YFC0704903; the National Natural Science Foundation of China, under grant no. 51778611; and the National Key R\&D Program Projects of China.

\section{References}

[1] H. H. Zhu, F. Peng, X. Li, and C. Liu, "Development strategy on UUS planning in China," Strategic Study of Chinese Academy of Engineering, vol. 19, no. 6, pp. 12-17, 2018.

[2] F. L. Peng, Y. K. Qiao, S. Sabri, B. Atazadeh, and A. Rajabifard, "A collaborative approach for UUS development toward sustainable development goals: critical dimensions and future directions," Frontiers of Structural and Civil Engineering, vol. 15, no. 4, pp. 20-45, 2021.

[3] Q. H. Qian, "Present state, problems and development trends of UUS in China," Tunnelling and Underground Space Technology, vol. 55, no. 5, pp. 280-289, 2016.

[4] Q. H. Qian, "Scientific use of the UUS to construction the harmonious livable and beautiful city," Hazard Control in Tunnelling and Underground Engineering, vol. 1, no. 1, pp. 1-7, 2019.

[5] Y. Liu, F. Dai, and P. Pei, “A wing-crack extension model for tensile response of saturated rocks under coupled static-dynamic loading," International Journal of Rock Mechanics and Mining Sciences, vol. 146, Article ID 104893, 2021.

[6] Z. Tao, Y. Shu, X. Yang, Y. Peng, Q. Chen, and H. Zhang, "Physical model test study on shear strength characteristics of slope sliding surface in Nanfen open-pit mine," International Journal of Mining Science and Technology, vol. 30, no. 3, pp. 421-429, 2020. 
[7] H. Yuan, Y. He, J. Zhou, Y. Li, and Z. Shen, "Research on compactness ratio model of UUS and compact development mechanism of rail transit station affected area," Sustainable Cities and Society, vol. 55, no. 10, pp. 1-30, 2020.

[8] Y.-K. Qiao, F.-L. Peng, S. Sabri, and A. Rajabifard, "Low carbon effects of urban underground space," Sustainable cities and society, vol. 45, no. 12, pp. 451-459, 2019.

[9] R. Zargarian, D. Hunt, P. Braithwaite, N. Bobylev, and C. Rogers, "A new sustainability framework for UUS," Proceedings of the Institution of Civil Engineers-Engineering Sustainability, vol. 171, no. 5, pp. 1-16, 2016.

[10] H. Yu, Y. Bao, and Y. H. Wang, "Analysis of geoenvironmental hazards in UUS development in Shanghai," Natural Hazards, vol. 75, no. 3, pp. 2067-2079, 2015.

[11] M.-s. Zhang, H. Q. Wang, H.-q. Wang et al., "Evaluation of urban underground space resources using a negative list method: taking Xi'an City as an example in China," China Geology, vol. 3, no. 1, pp. 124-136, 2020.

[12] Y. Xu and X. Chen, "Quantitative analysis of spatial vitality and spatial characteristics of urban underground space (UUS) in metro area," Tunnelling and Underground Space Technology, vol. 111, no. 10, Article ID 103875, 2021.

[13] L. He, Y. Song, S. Dai, and K. Durbak, "Quantitative research on the capacity of urban underground space - the case of Shanghai, China," Tunnelling and Underground Space Technology, vol. 32, no. 6, pp. 168-179, 2012.

[14] F. V. D. Hoeven and A. Van Nes, "Improving the design of UUS in metro stations using the space syntax methodology," Tunnelling and Underground Space Technology, vol. 40, no. 9, pp. 64-74, 2013.

[15] D. V. L. Hunt, I. Jefferson, and C. D. F. Rogers, “Assessing the sustainability of underground space usage - a toolkit for testing possible urban futures," Journal of Mountain Science, vol. 8, no. 2, pp. 211-222, 2011.

[16] Y.-K. Qiao, F.-L. Peng, and Y. Wang, "Monetary valuation of urban underground space: a critical issue for the decisionmaking of urban underground space development," Land Use Policy, vol. 69, no. 8, pp. 12-24, 2017.

[17] P. Bélanger, "Underground landscape: the urbanism and infrastructure of Toronto's downtown pedestrian network," Tunnelling and Underground Space Technology, vol. 22, no. 3, pp. 272-292, 2007.

[18] R. Kimmo, J. Ritola, and K. Rauhala, "Underground space in land-use planning," Tunnelling and Underground Space Technology, vol. 13, no. 1, pp. 39-49, 1998.

[19] D. V. L. Hunt, L. O. Makana, I. Jefferson, and C. D. F. Rogers, "Liveable cities and urban underground space," Tunnelling and Underground Space Technology, vol. 55, no. 5, pp. 8-20, 2016.

[20] H. Admiraal and A. Cornaro, "Why underground space should be included in urban planning policy - and how this will enhance an urban underground future," Tunnelling and Underground Space Technology, vol. 55, no. 5, pp. 214-220, 2016.

[21] X. Wang, F. Zhen, X. Huang, M. Zhang, and Z. Liu, "Factors influencing the development potential of urban underground space: structural equation model approach," Tunnelling and Underground Space Technology, vol. 38, no. 6, pp. 235-243, 2013.

[22] Y. Liu and F. Dai, "A review of experimental and theoretical research on the deformation and failure behavior of rocks under cyclic loads," Journal of Rock Mechanics and Geotechnical Engineering, vol. 13, no. (5), pp. 1203-1230, 2021.
[23] D. J. Boivin, "Montreal's underground network: a study of the downtown pedestrian system," Tunnelling and Underground Space Technology, vol. 6, no. 1, pp. 83-91, 1991.

[24] S. E. Polzin, "Transportation/land-use relationship: public transit's impact on land use," Journal of Urban Planning and Development, vol. 125, no. 4, pp. 135-151, 1999.

[25] J. B. Admiraal, "A bottom-up approach to the planning of underground space," Tunnelling and Underground Space Technology, vol. 21, no. 3, pp. 464-465, 2006.

[26] J. Peng and F.-L. Peng, "Layout Patterns of Underground Space Comprehensive Utilization Around Metro Station for Urban Commercial Area," in Proceedings of the GeoShanghai 2018 International Conference:Tunnelling and Underground Construction, pp. 587-596, Springer, Manhattan, NY, USA, January,2018.

[27] G.-L. Jia, R.-G. Ma, and Z.-H. Hu, "Review of urban transportation network design problems based on CiteSpace," Mathematical Problems in Engineering, vol. 2019, Article ID 5735702, 22 pages, 2019.

[28] Y.-H. Dong, F.-L. Peng, Y.-K. Qiao, J.-B. Zhang, and $\mathrm{X}$.- $\mathrm{L}$. Wu, "Measuring the monetary value of environmental externalities derived from urban underground facilities: towards a better understanding of sustainable underground spaces," Energy and Buildings, vol. 250, no. 1, Article ID 111313, 2021.

[29] Y. P. Hu, K. X. Zhang, J. Yang, and Y. H. Wu, "Application of hierarchical facility location-routing problem with optimization of an underground logistic system: a case study in China," Mathematical Problems in Engineering, vol. 2018, Article ID 7235048, 10 pages, 2018.

[30] S.-C. Liu, F.-L. Peng, Y.-K. Qiao, and J.-B. Zhang, "Evaluating disaster prevention benefits of underground space from the perspective of urban resilience," International Journal of Disaster Risk Reduction, vol. 58, no. 5, Article ID 102206, 2021.

[31] Y. K. Qiao, F. L. Peng, X. L. Wu, and S. F. Ding, "Underground space planning in urban built-up areas: a case study of Qingdao, China," in Proceedings of the 16th World Conference of the Associated Research Centers for the Urban Underground Space (ACUUS), 16th ACUUS Conference Organizing Committee, Hong Kong, China, November 2018.

[32] G. Golany, Urban Underground Space Design in China: Vernacular and Modern Practice, University of Delaware Press, Newark, Delaware, 1989.

[33] N. Bobylev, "Transitions to a high density urban underground space," Procedia Engineering, vol. 165, no. 10, pp. 184-192, 2016.

[34] L. He, S. Z. Dai, and Y. Shu, "Discussion on some problems of UUS planning," Chinese Journal of Underground Space and Engineering, vol. 31, no. 5, pp. 825-829, 2011, in Chinese.

[35] J. X. Zheng, C. Wang, and Y. Sun, "Research on key control elements of UUS planning - - takes Tianjin Xiaobailou area as an example," Chinese Journal of Underground Space and Engineering, vol. 32, no. 5, pp. 889-895, 2012, in Chinese.

[36] H. Yuan, S. Z. Dai, and X. R. Liu, "Study on underground space in chongqing," Chinese Journal of Underground Space and Engineering, vol. 34, no. 1, pp. 1-5, 2014, in Chinese.

[37] G. Y. Cai, Q. Y. He, and J. H. Yao, "Preparation system and content of underground space planning from the spatial and temporal perspective," Chinese Journal of Underground Space and Engineering, vol. 37, no. 5, pp. 1145-1149, 2017, in Chinese.

[38] Z.-L. Chen, J.-Y. Chen, H. Liu, and Z.-F. Zhang, "Present status and development trends of underground space in 
Chinese cities: evaluation and analysis," Tunnelling and Underground Space Technology, vol. 71, no. 8, pp. 253-270, 2018.

[39] G. Swensen, "Tensions between urban heritage policy and compact city planning - a Practice review," Planning Practice and Research, vol. 35, no. 5, pp. 555-574, 2020.

[40] Z. Chen, L. Su, and C. Zhang, "Research on the synergy degree of aboveground and underground space along urban rail transit from the perspective of urban sustainable development," Sustainability, vol. 8, no. 9, p. 934, 2016.

[41] M. Vidó, T. Hámor, and L. Czirok, "Underground space, the legal governance of a critical resource in circular economy," Resources Policy, vol. 73, no. 10, Article ID 102171, 2021.

[42] X. Wang, X. J. Huang, and J. Tang, "Fuzzy synthesis evaluation on the development potential of UUS resource," Journal of Beijing University of Technology, vol. 36, no. 2, pp. 213-218, 2010, in Chinese.

[43] H. Xie, Y. Zhang, Y. Chen, Q. Peng, Z. Liao, and J. Zhu, “A case study of development and utilization of urban underground space in Shenzhen and the Guangdong-Hong KongMacao Greater Bay Area," Tunnelling and Underground Space Technology, vol. 107, no. 1, Article ID 103651, 2021.

[44] R. K. Singh, H. R. Murty, S. K. Gupta, and A. K. Dikshit, "An overview of sustainability assessment methodologies," Ecological Indicators, vol. 9, no. 2, pp. 189-212, 2009.

[45] O. Vitor and P. Pinho, "Evaluation in urban planning: advances and prospects," Journal of Planning Literature, vol. 24, no. 4, pp. 343-361, 2010.

[46] X. Hong, X. Ji, and Z. Wu, "Architectural colour planning strategy and planning implementation evaluation of historical and cultural cities based on different urban zones in Xuzhou (China)," Color Research \& Application, vol. 46, no. 6, Article ID 22736, 2021.

[47] P. Sajida, M. Kamruzzaman, and T. Yigitcanlar, "Developing policy scenarios for sustainable urban growth management: a Delphi approach," Sustainability, vol. 9, no. 10, pp. 343-361, 2017.

[48] J. S. Deng, K. Wang, Y. H. Deng, and G. J. Qi, "PCA-based land-use change detection and analysis using multitemporal and multisensor satellite data," International Journal of Remote Sensing, vol. 29, no. 16, pp. 4823-4838, 2008.

[49] Y. Wang, J. Li, G. Zhang, Y. Li, and M. H. Asare, "Fuzzy evaluation of comprehensive benefit in urban renewal based on the perspective of core stakeholders," Habitat International, vol. 66, no. 6, pp. 163-170, 2017.

[50] Y. Liu, R. Li R, and X. Song, "Grey associative analysis of regional urbanization and eco-environment coupling in China," Acta Geographica Sinica, vol. 60, no. 2, pp. 237-247, 2005.

[51] D. Ouyang, X. Zhu, X. Liu, R. He, and Q. Wan, "Spatial differentiation and driving factor Analysis of urban construction land change in county-level city of guangxi, China," Land, vol. 10, no. 7, p. 691, 2021.

[52] B. Wout, "Urban underground space: solving the problems of today's cities," Tunnelling and Underground Space Technology, vol. 55, no. 5, pp. 245-248, 2016.

[53] M. Z. Gao, J. Xie, J. Guo, Y. Q. Lu, Z. Q. He, and C. Li, “Fractal evolution and connectivity characteristics of mining-induced crack networks in coal masses at different depths," Geomechanics and Geophysics for Geo-Energy and Geo-Resources, vol. 7, no. 1, 2021.

[54] M. Z. Gao, J. Xie, Y. N. Gao et al., "Mechanical behavior of coal under different mining rates: a case study from laboratory experiments to field testing," International Journal of Mining Science and Technology, vol. 31, no. 2021, pp. 825-841, 2021.
[55] R. L. Schalock, M. A. Verdugo, and J. van Loon, "Understanding organization transformation in evaluation and program planning," Evaluation and Program Planning, vol. 67, no. 4, pp. 53-60, 2018.

[56] G. Kimia, M. Hamzenejad, and A. Meshkini, "An analysis of the spatial distribution pattern of social-cultural services and their equitable physical organization using the TOPSIS technique: the case-study of Tehran, Iran," Sustainable Cities and Society, vol. 51, no. 11, Article ID 101708, 2019.

[57] X. Li, K. Peng, J. Peng, and H. Xu, "Effect of cyclic wettingdrying treatment on strength and failure behavior of two quartz-rich sandstones under direct shear," Rock Mechanics and Rock Engineering, vol. 54, no. 11, pp. 5953-5960, 2021.

[58] X. Li, K. Peng, J. Peng, and D. Hou, "Experimental investigation of cyclic wetting-drying effect on mechanical behavior of a medium-grained sandstone," Engineering Geology, vol. 293, Article ID 106335, 2021.

[59] C. Zhu, M. C. He, Z. G. Tao, Q. X. Meng, and X. H. Zhang, "Recognition and prevention of rockfall vulnerable area in open-pit mines based on slope stability analysis," Geomechanics and Engineering, vol. 26, no. 5, pp. 441-452, 2021.

[60] C. Zhu, K. Zhang, H. Cai et al., "Combined application of optical fibers and CRLD bolts to monitor deformation of a pitin-pit foundation," Advances in Civil Engineering, vol. 2019, no. 1, 16 pages, Article ID 2572034, 2019.

[61] Z. B. Wang, "Land spatial development based on carrying capacity, land development potential, and efficiency of urban agglomerations in China," Sustainability, vol. 10, no. 2, p. $4701,2018$.

[62] L. Wu, H. Xia, X. Cao, C. Zhang, and C. Dai, "Research on quantitative demand of underground space development for urban rail transit station areas: a case study of metro line 1 in Xuzhou, China," Urban Rail Transit, vol. 4, no. 4, pp. 257-273, 2018. 